\title{
Electric Field Stress in a Three Phase Common Enclosure Gas Insulated Busduct with FGM Post Type Spacer and Reduction with Metal Inserts
}

\author{
Polamraju V. S. Sobhan ${ }^{1}$. Janaki Pakalapati ${ }^{2}$. Venkata Nagesh Kumar Gundavarapu ${ }^{3}$. Deepak Chowdary Duvvada ${ }^{4}$. \\ Sravana Kumar Bali ${ }^{5}$
}

Received: 8 June 2020 / Revised: 3 November 2020 / Accepted: 3 December 2020 / Published online: 14 December 2020

(c) The Author(s) 2020

\begin{abstract}
The establishment of supporting insulators plays a vital role in the continuous operation of the three-phase Gas Insulated Busduct (GIB), which primarily depends on the distribution of electric field stress on the spacer surface. Shape control is a technique used along the spacer surface to achieve uniform field intensity, but this technique can also lead to very irregular shapes. The Triple Junction (TJ) is the region where the field stress has to be reduced. Over a period, high field stresses along the spacer surface will result in a surface flashover and thus de-energize the complete GIB, leading to enormous losses economically. In this paper, a Functionally Graded Material (FGM) spacer for a three-phase GIB has been designed with more number of gradings and further field stress at TJ is minimized by inserting and reshaping the metal inserts (MI) at the end of the enclosure. By doping them with different permittivity values, functionally graded materials are spatially distributed with multiple filler materials to achieve uniform stress on the electric field. Simulation is carried out with the FGM and epoxy (post type) Spacers for different voltages and FGM gradings. With MI, the stress is minimized and an enhanced uniform field allocation along the surface is obtained.
\end{abstract}

Keywords Functionally graded material (FGM) - Post type spacer · Electric field distributions · Dielectric materials . Insulators · Gas insulated substations · Triple junction · Enclosure · Electric field stress · Uniform field

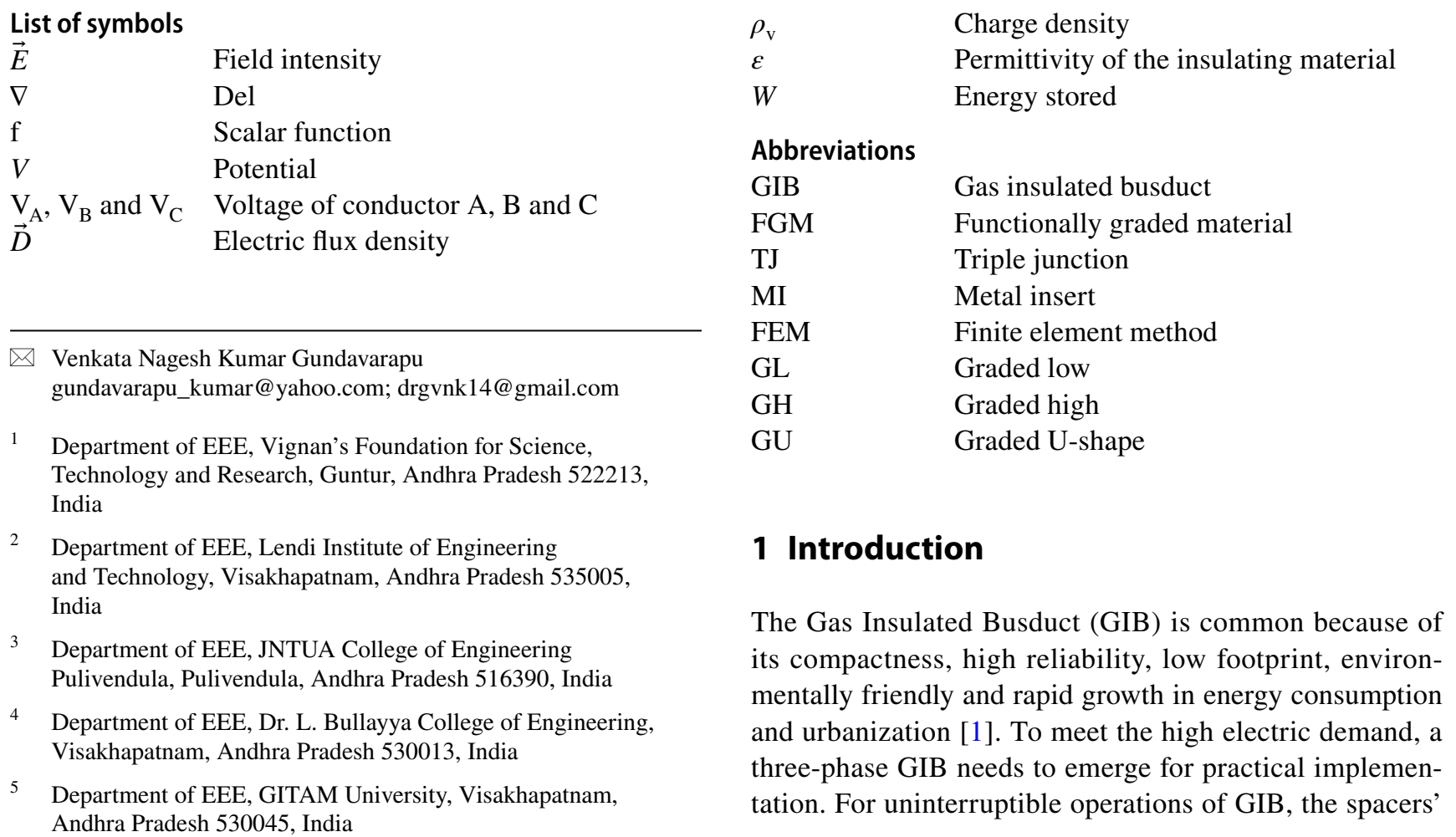


performance has to be improved as it provides mechanical support to spacers. An appropriate design of spacers has to be chosen to overcome its failures due to several defects under various operating conditions. An appropriate method has to be implemented to identify the defects of insulators with impulse voltages to reduce the electric field intensity due to these failures [2-4]. Some reviewers [5, 6] has reviewed that the solid spacers provide the conductors and the enclosure with mechanical support. The distribution of electric fields in the spacer contributes to spacer failures. The existence of these solid insulators contributes to the inappropriate distribution of electrical fields distressing the complete GIB, in particular, because of unavoidable defects such as delamination, void, conductive particles etc.

In literature, several authors studied on the electric field intensity in GIB and its reduction in various insulators like a cone, disc type lost their dielectric strength due to insulator contamination. However, the above types of spacers have found to be more complicated. In addition to this, Zihao Guo et al. [7] have reviewed that the transmission capability of the gas-insulated transmission line (GIL) increases with the improvement of dielectric and mechanical strengths of GIL insulators. This happens due to uniform electric field distribution and the decrease of surface flashover strength. The surface charge accumulation in compressed $\mathrm{SF}_{6}$ gasinsulated devices create major problems like surface flashover, dielectric failures during manufacturing, installation, and operation process [8-10]. Muneaki Kurimoto et al. [11] identified that the power equipment in GIB can be compact based on the field distribution around the spacer. Further, this is achieved by using the GU-FGM technique with an efficient method called $\varepsilon$-FGM at the junction of the electrode surface and solid dielectrics i.e. at TJ's to maintain the uniform field. In this context, Du et al. [12] has recognized different methods of grading the FGM spacers, like $\varepsilon$ FGM, $\sigma \mathrm{FGM},(\varepsilon / \sigma) \mathrm{FGM}$ and frequency variation method for the design of cone type spacers. Ju et al. [13] studied that FGM was used as an insulator by varying the permittivity of FGM. The concentration of the Electric field can be decreased at the specific region by replacing the grounded round electrode with elliptical FGM spacer. Consequently, the electrical field near TJ of the enclosure end is reduced. Naoki Hayakawa et al. [14] recognized this new technique of FGM, uses permittivity distribution as a controlling factor for the field distribution in GIB spacers. As a result, it has given good results for the FGM at various special distributions both in fabrication and simulation approaches. However, this is implemented in the design of a single-phase gas-insulated busduct. Naoki Hayakawa et al. [15] have observed $\varepsilon$ FGM as the efficient method for reducing the field stress over the length of the spacer. Zhaoyu Ran et al. [16] proposed a simplified design of an insulator with a surface graded functional material (SFGM) to suppress electric distortion at the triple junction of the superconducting gas-insulated transmission line(S-GIL) by using FEM. The focus on modelling of the proper spacer has made by Zhenlian et al. [17] and reviewed the performance of Electric parameters of unfilled epoxy insulators to improve it by using alumina filled epoxy composites in $\mathrm{SF}_{6}$ gas-insulated systems.

In spite of this Lin Liu et al. [18] observed TJ as the weakest part in gas-insulated systems with complexity in the physical process affected by flashovers. In particular, Chakravorti et al. [19], has stated that with some efforts are needed to develop uniform field intensity at Triple Junctions (TJ's) which capable by incorporating metal insert. Several authors $[20,21]$ have considered a technique to minimize electrical field stress by incorporating the metal insert, which could reduce the electrical field successfully near the triple junction of the spacer. Estimations have been made on epoxy spacers, spacers with an imperfection at the TJ comes about unmistakably demonstrated that metal supplements moved the most extreme field to the mid hole locale. In addition, metal supplements have been found to provide good TJ protection, if the elevated stress remains below the allowable level.

Imai et al. [22, 23] developed a new technology with FGM for the design of insulation materials by tailoring two kinds of epoxy-based resins with different relative permittivities for cone type spacers. Du et al. [24, 25] has introduced a new concept of surface functionally graded material by depositing $\mathrm{BaTiO}_{3}$ on the insulator surface to have a uniform field distribution. To improve HVDC gas-insulated lines, the fabrication technique under the deposition of $\mathrm{ZnO}$ films by a magnetron sputtering method is used. In another study, the investigation of numerical methods for the computation of the Electric field using Laplace's equation and Poisson's equation is flexible rather than an analytical approach by using one of the numerical methods like FEM. However, FGM technique the grading with epoxy spacer at different permittivity values is done by using FEM analysis [26-28].

Many researchers have worked on the above aspects for only single-phase Gas Insulated Substations. The FGM spacer is a modern technique, which is used by modulating the permittivity values to decrease the electric field strength. The FGM spacer is a modern technique, which is used by modulating the permittivity values to decrease the electric field strength. By using this grading technique with a proper range of permittivity, the field pressure can be decreased at the appropriate location. It is anticipated to extend these concepts of FGM spacer, computation of electric field in the design of three-phase GIB. By using FGM spacer, uniform electric field intensity can be achieved all over the spacer. The electric field intensity on the FGM spacer can be minimized by using Metal Inserts at Triple Junction.

In this paper, a detailed analysis has been done on a post/epoxy type spacer and FGM spacer in special 
configurations like GL-FGM, GH-FGM, and GU-FGM in three-phase GIB. Simulation is done by constructing a three-phase GIB by assigning conductors and enclosures with appropriate charge conservation. After computing the designed model, the characteristics have been analyzed for electric field intensity at enclosure end at TJ of epoxy and FGM spacers. At the triple junction and conductor end, the electrical field strength produced by both the spacers is analyzed. The same procedure is applied for all ranges of permittivity for three conductors. The high electric field intensity is observed at $\mathrm{TJ}$, a particular dimensioned $\mathrm{MI}$ is inserted at the enclosure end to reduce this effect.

\section{Governing Equations of Three Phase GIB Using Fem Technique}

The electrical field intensity of a three phase GIB is calculated by using Laplace's equation or poison's equation under boundary conditions applied to the common enclosure. The Laplace's equation is found to be simple and easy for proceeding with an analytical approach than Poisson's equation. Despite several numerical methods, FEM is identified as the most convenient method for simplifying complex problems. Here FEM is used to calculate the electrical field intensity over the spacer surface. The scalar electric potential is established for the electric field in electrostatic studies, for which Maxwell's first equation in differential form is reduced as

$\nabla \times \vec{E}=0$

From the properties of the field operators, we obtain

$\nabla \times(\nabla f)=0$

which establishes that the curl of the gradient of any scalar function (f) is identically null.

Thus, the electric field of Eq. (1) is a derivate of the gradient of a function called as electric potential function so that

$\vec{E}=-\operatorname{grad}(V)=-\nabla V$

Then $\nabla \times(\nabla V)=0$

$\nabla \cdot \vec{D}=\rho_{v}$

$\vec{D}=\varepsilon \vec{E}$

where $\varepsilon=\varepsilon_{o} \varepsilon_{r}$ is permittivity of the insulating material in Farad/ meter.

Equation (7) is obtained by substituting Eq. (6) in Eq. (5) $\nabla \cdot \vec{E}=\frac{-\rho_{v}}{\varepsilon}$

$\nabla \cdot(-\nabla V)=\frac{-\rho_{v}}{\varepsilon}$

So the Eq. (8) can be cut down into Poisson's equation given by Eq. (9)

$\nabla^{2} V=\frac{-\rho_{v}}{\varepsilon}$

At zero charge density, Eq. (9) can be cut down to Laplace's equation as represented in Eq. (10)

$\nabla^{2} V=0$

\section{Electric Field Computation}

Finite Element Method is one of the boundary subdivision the method which usually have more reliable electric fields than domain subdivision methods (finite difference method and the binary element method). Galerkin's method is used as an optimization strategy to change the profile of the spacer. In order to render smooth operations of the post-type spacer is been streamlined by placing constraints on the column cross-sections of the spacer. Potential values can only be symmetric about the symmetry planes if the normal derivative of potential vanishes there. Thus the boundary-value problem to be solved consists of Fig. 1, subject to the boundary conditions for symmetry planes is given by

$\frac{\partial V}{\partial n}=0$

The well-known principle of minimum potential energy requires the potential $\mathrm{V}$ to distribute itself in the three-phase GIB in such a way as to minimize the energy stored. By using the Laplace Equation, in the steady-state electrostatics with a constant dielectric material, the electric energy stored is obtained by integrating it out over the whole two-dimensional problem region as shown in Eq. (12).

$W=\frac{1}{2} \int_{S} \varepsilon(\nabla V \cdot \nabla V) d S$

This minimum energy principle is mathematically equivalent to Laplace's equation, in the sense that a potential distribution and represented as

$W=\frac{1}{2} \int_{S}\left(\varepsilon_{x} \frac{\partial^{2} V}{\partial x^{2}}+\varepsilon_{y} \frac{\partial^{2} V}{\partial y^{2}}\right) d x d y$

By substituting Laplace's Equation in Eq. (12), 
Fig. 1 Design model three phase GIB

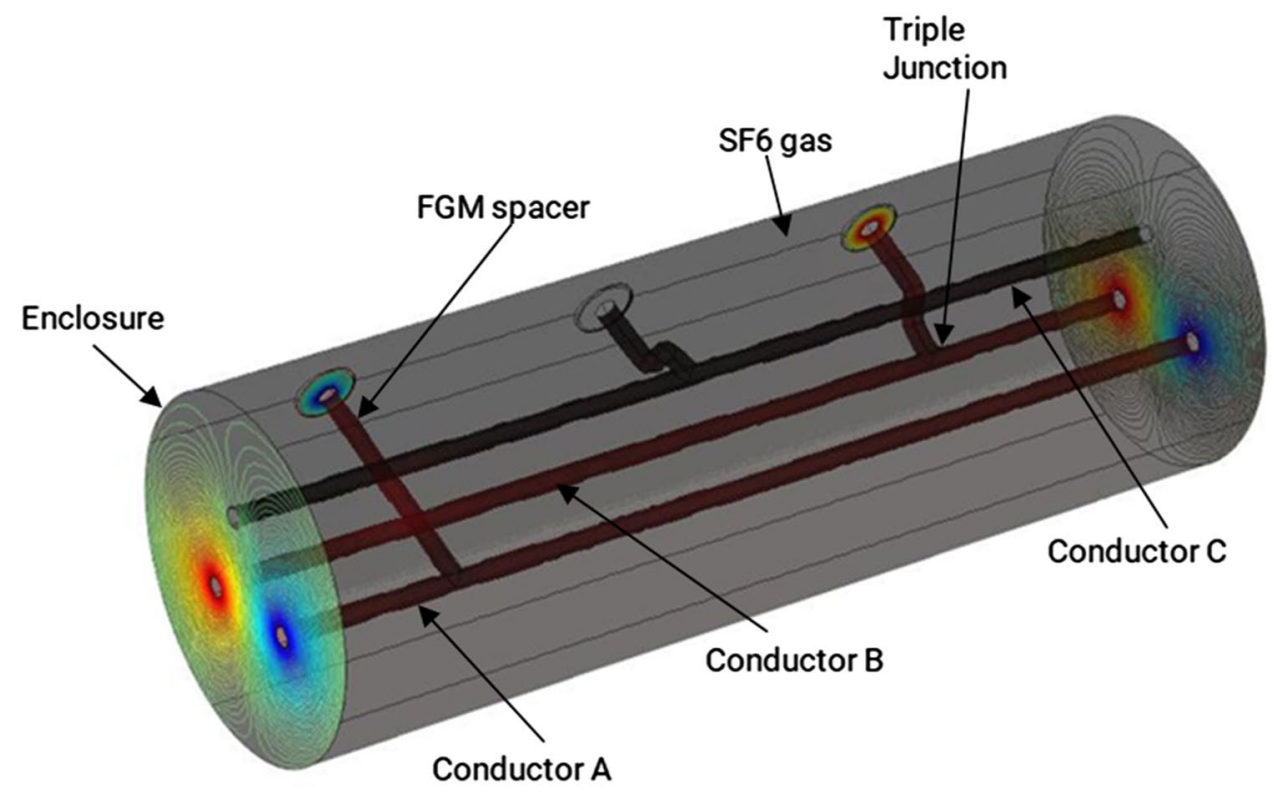

$d W=\frac{1}{2} \int_{S} \varepsilon\left(\nabla^{2} V\right) d x d y=0$

Therefore $d W=0$.

\section{Post Type Functionally Graded Material Spacer}

Post type spacers are one of the simplest insulators used in GIB when compared to other insulators like cone form, disc form spacers. This spacer is designed between the conductor end and the enclosure end, which is elevated perpendicularly. The distribution of the Electric field along the post type spacer is uniform under normal conditions and equal to the average field strength. The main drawback of the post type spacer is that it provides the shortest possible creeping distance in the event of a flashover between the live conductor and the outer enclosure as it with uniform permittivity. In the event of flashovers, the electric field distribution may be uneven due to high permittivity of spacer material than that of the surrounding gas. To reduce this electric field intensification along the interface surface, the relative permittivity of the spacer is redistributed across the spacer medium by using FGM technique. The FGM spacer with post type structure is designed with 20 equal gradings for all the three spacers as per lengths. The effect of FGM gradings is done by using GL, GH and GU for ranges of permittivity. The mathematical analysis of the Electric field has been calculated by using FEM as mentioned in the above section. The stepwise procedure for the simulation of the Post type FGM spacer is given below.
Step-1: The basic three-phase GIB model is designed with epoxy post type spacers on which the three conductors are mounted.

Step- 2: The three-post type spacers are graded into 20 equal gradings with dissimilar permittivity's as represented in Table 1 to generate uniform electrical field throughout the spacer length.

Step- 3: The above step 2 is repeated for different ranges of permittivity for Graded Low, Graded High and Graded U-shape FGM gradings.

In this paper, three distinct classes such as GL-FGM, GU-FGM and GU-FGM, are intended for the effectiveness of FGM. In GL- FGM the permittivity value is increasingly decreased from the end of the conductor to the end of the enclosure. Whereas the permittivity value in GH-FGM is gradually improved from the conductor to enclosure ends and in GU-FGM the permittivity value is gradually reduced from the end of the conductor to the middle of the FGM spacer and then gradually increased towards the end of the enclosure.

Table 1 Permittivity ranges of FGM post type spacer

\begin{tabular}{llll}
\hline Grading type & \multicolumn{3}{l}{ Permittivity ranges } \\
\cline { 2 - 4 } & Case I & Case II & Case III \\
\hline GL-FGM & 2.3 to 4.2 & 2.4 to 4.3 & 2.5 to 4.4 \\
GH-FGM & 2.5 to 4.4 & 2.4 to 4.3 & 2.3 to 4.2 \\
GU-FGM & 4.2 to 3.3 to 4.2 & 4.3 to 3.4 to 4.3 & 4.4 to 3.5 to 4.4 \\
\hline
\end{tabular}




\subsection{Graded Low-FGM (GL-FGM)}

Permittivity at the conductor end is retained at high value and the enclosure end is steadily reduced as shown in Fig. 2. The permittivity range is taken to be a minimum value of 2.3 and a maximum value of 4.2. For three different cases with different ranges of permittivity, GL grading is preserved, as shown in Table 1 . The equations pertaining to the case I, case II and case III of GL grading are $y=-0.1 x+4.3$, $y=-0.1 x+4.4$ and $y=-0.1 x+4.5$ respectively.

\subsection{Graded High-FGM (GH-FGM)}

Permittivity is retained at the conductor end at a low value and, as shown in Fig. 3, is steadily increased towards enclosure end. The range of permittivity shall be taken as a minimum value of 4.2 and a maximum value of 2.3. In three different cases, the GH rating is maintained with different allowability ranges as shown in Table 1 . The equations pertaining to the case I, case II and case III of GH grading are, and respectively.

\subsection{Graded U Shape-FGM}

Permittivity is reduced as shown in Fig. 4 from high value to centre value and then the minimum value from the end of the conductor to the end of the enclosure. The permittivity range is taken from a high 4.2 to a 3.3 centre value and then increased to a 4.2. For three different cases, the GU grading is maintained by dissimilar permittivity ranges, as shown in Table 1 . The equations pertaining to the case I, case II and case III of GH grading are $y=0.009 x^{2}-0.197 x+4.473 y=0.009 x^{2}-0.197 x+4.573$ and $y=0.009 x^{2}-0.197 x+4.673$ respectively.

\section{Results and Discussions}

\subsection{Model of Three- Phase GIB for Simulation}

The simulation model for the three-phase gas-insulated busduct is taken with a radius of $225.5 \mathrm{~mm}$ of the enclosure with SF6 gas insulation and a relative permittivity of 1.0015 . The three conductors are enclosed within a common enclosure each with $38.66 \mathrm{~mm}$ as the inner radius. The length of the spacer between the conductor $\mathrm{A}, \mathrm{B}$ and $\mathrm{C}$ is considered to be $193.8 \mathrm{~mm}, 43 \mathrm{~mm}$, and $193.8 \mathrm{~mm}$ respectively and $26 \mathrm{~mm}$ wide. The designed GIB is simulated by FEM analysis and its simulation model is as represented in Fig. 5 of which the spacer material is epoxy-alumina composite.

In the proposed model, all the conductors are placed at equidistant to each other and under balanced conditions inside the common enclosed GIB. Conductor $\mathrm{A}$ is applied with the root mean square voltage of $\mathrm{V}_{\mathrm{A}}$ equal to $72.5 \mathrm{kV}$, $132 \mathrm{kV}$ and $220 \mathrm{kV}$. The outer electrode is grounded to zero potential. The corresponding maximum voltage of three conductors to the considered root mean square voltage is shown in Table 2. Further, to create uniform electrical field intensity over the post type spacer, FGM technique is used for the above-mentioned dimensions of GIB.

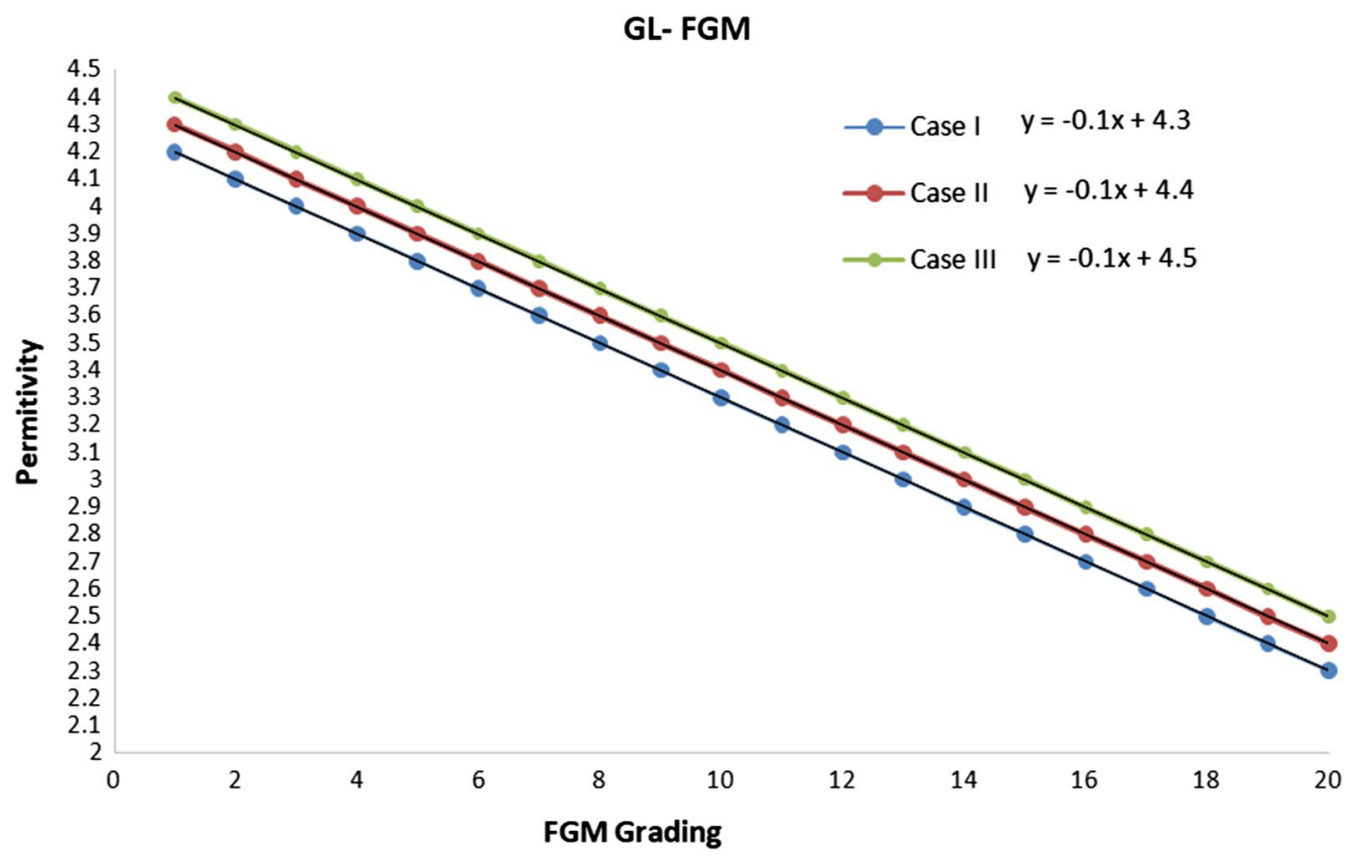

Fig. 2 Permittivity variation of graded low FGM 


\section{GH- FGM}

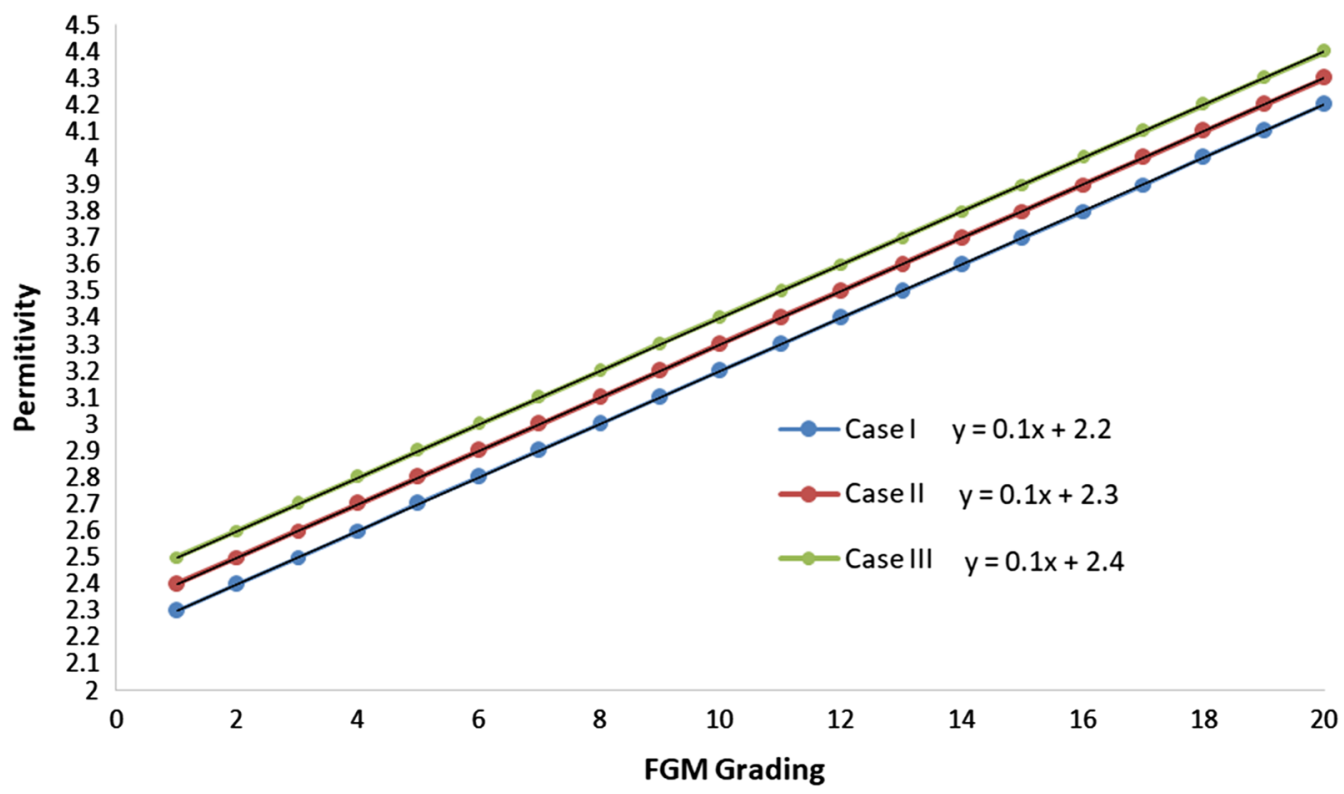

Fig. 3 Permittivity variation of graded high FGM

\section{GU- FGM}

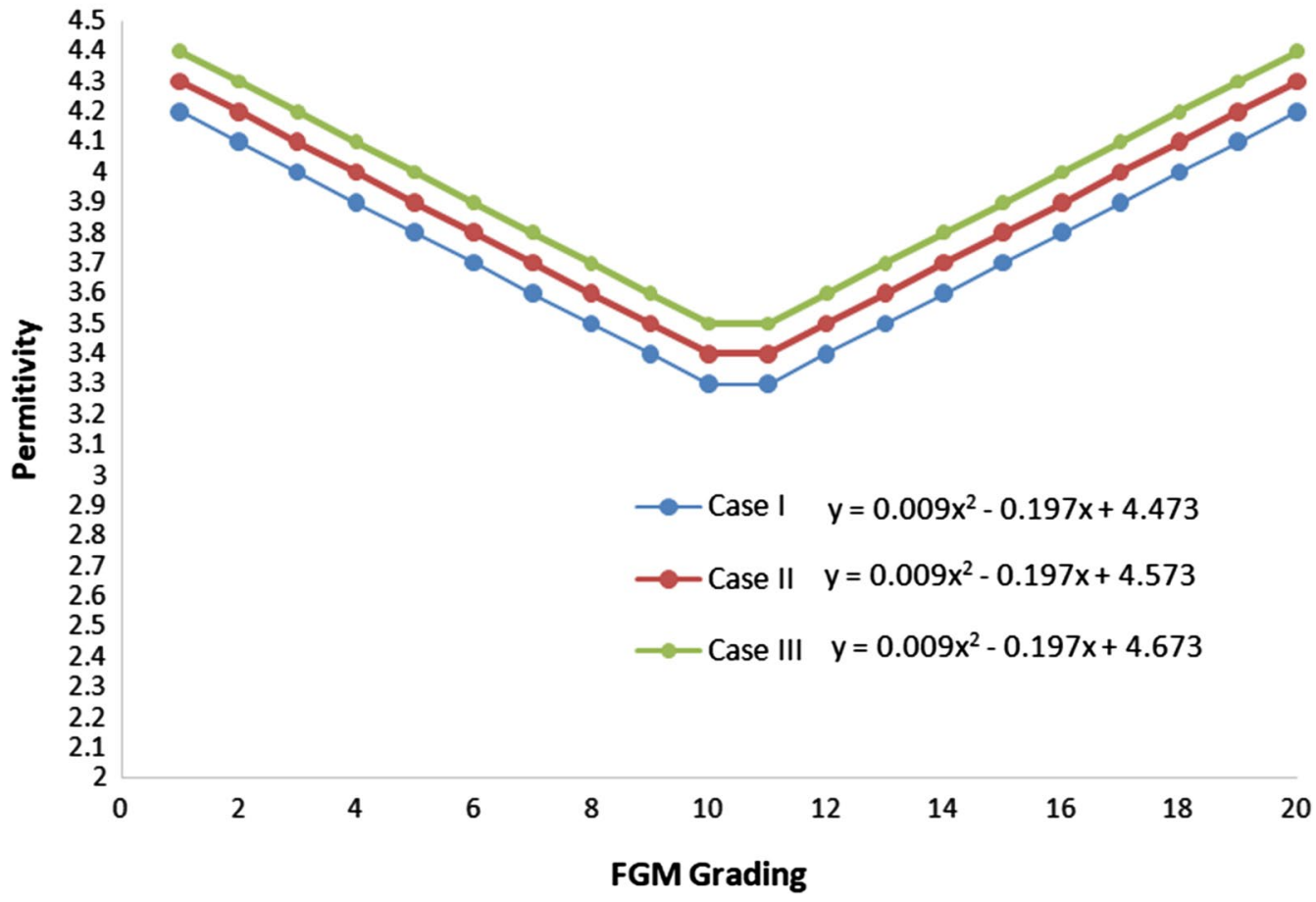

Fig. 4 Permittivity variation of graded U shape FGM

\subsection{Epoxy/Plain Spacer}

The designed epoxy type spacer under constant permittivity of 4.5 is simulated. The applied voltages are $\mathrm{V}_{1}, \mathrm{~V}_{2}$ and $\mathrm{V}_{3}$. The field intensity is noticed at both ends of the three conductors. TJ formed at the enclosure end must be reduced with its electric field in the proposed three-phase GIB. 
It is observed from Table 3 that the electric field strength is high at TJ. Mainly it is noticed that conductor $B$ gives high field intensity at enclosure end as it is located very nearer to the enclosure. It is also noticed that field intensity at the conductor $\mathrm{A}$ is maximum because of the maximum voltage at conductor A comparatively from the Table 1 maximum voltages if $\mathrm{V}_{1}=72 \mathrm{kV}$ are observed as $\mathrm{V}_{\mathrm{A}}=102.515 \mathrm{kV}, \mathrm{V}_{\mathrm{B}}=-1.257 \mathrm{kV}$ and $\mathrm{V}_{\mathrm{C}}=-51.257 \mathrm{kV}$ respectively. Figure 6 represents the electrical field intensity of post type spacer without MI, which represents the magnitude of electrical field intensity is high at the enclosure end for the three conductors within in the range of 0.02 to $0.32 \mathrm{kV} / \mathrm{cm}$ at different applied voltages.

\subsection{Epoxy Type Spacer with MI}

The results of post/epoxy type spacer without metal insert have been obtained with high electrical field intensity at enclosure for three conductors A, conductor B, and conductor $\mathrm{C}$. A recessed metal insert is designed with a twodimensional combination of rectangular $(18 \mathrm{~mm} \times 4 \mathrm{~mm})$ and ellipse (a-axis of $11 \mathrm{~mm}, \mathrm{~b}$-axis of $3 \mathrm{~mm}$ ) at the enclosure of the three conductors are arranged to minimize the field intensity at $\mathrm{TJ}$ for the three conductors to reduce electrical field intensity as shown in Fig. 7. From Tables 3 and 4 , it is observed that the field intensity at $\mathrm{TJ}$ near the enclosure end is reduced at three conductors whereas no reduction is observed at the conductor ends as there is no impact of the MI at the HV conductors. It is also noticed

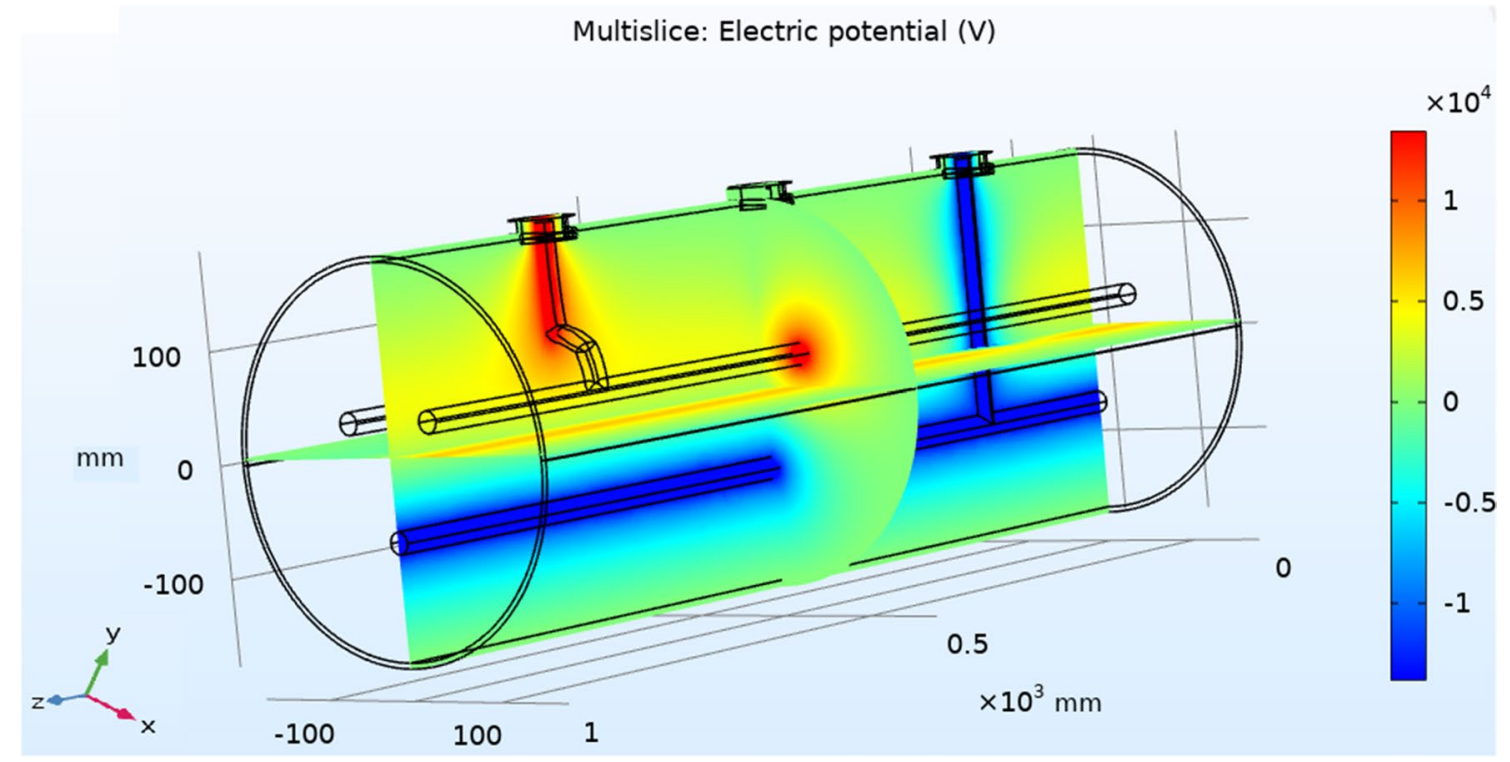

Fig. 5 Simulation model three phase GIB

Table 2 Maximum voltages of conductor A, B, C

\begin{tabular}{llll}
\hline $\begin{array}{l}\text { Root Mean Square Volt- } \\
\text { age }(\mathrm{kV})\end{array}$ & Maximum $\mathrm{V}_{\mathrm{A}}(\mathrm{kV})$ & Maximum $\mathrm{V}_{\mathrm{B}}(\mathrm{kV})$ & Maximum $\mathrm{V}_{\mathrm{C}}(\mathrm{kV})$ \\
\hline $\mathrm{V}_{1}=72.5$ & 102.515 & -51.258 & -51.258 \\
$\mathrm{~V}_{2}=132$ & 186.65 & -93.324 & -93.324 \\
$\mathrm{~V}_{3}=220$ & 311.08 & -155.54 & -155.54 \\
\hline
\end{tabular}

Table 3 Electrical field intensity of plain post type spacer

\begin{tabular}{|c|c|c|c|c|c|c|}
\hline \multirow[t]{2}{*}{ Conductor } & \multicolumn{2}{|l|}{$\mathrm{V}_{1}=72.5 \mathrm{kV}$} & \multicolumn{2}{|l|}{$\mathrm{V}_{2}=132 \mathrm{kV}$} & \multicolumn{2}{|l|}{$\mathrm{V}_{3}=220 \mathrm{kV}$} \\
\hline & $\mathbf{E}_{\text {enclosure }}(\mathrm{kV} / \mathrm{cm})$ & $\mathbf{E}_{\text {conductor }}(\mathrm{kV} / \mathrm{cm})$ & $\mathbf{E}_{\text {enclosure }}(\mathrm{kV} / \mathrm{cm})$ & $\mathbf{E}_{\text {conductor }}(\mathrm{kV} / \mathrm{cm})$ & $\mathbf{E}_{\text {enclosure }}(\mathrm{kV} / \mathrm{cm})$ & $\mathbf{E}_{\text {conductor }}(\mathrm{kV} / \mathrm{cm})$ \\
\hline A & 0.0084 & 0.1681 & 0.0153 & 0.30608 & 0.0255 & 0.51015 \\
\hline B & 0.10645 & 0.14605 & 0.1938 & 0.2659 & 0.3231 & 0.4432 \\
\hline C & 0.03485 & 0.1175 & 0.0635 & 0.21395 & 0.10585 & 0.3566 \\
\hline
\end{tabular}




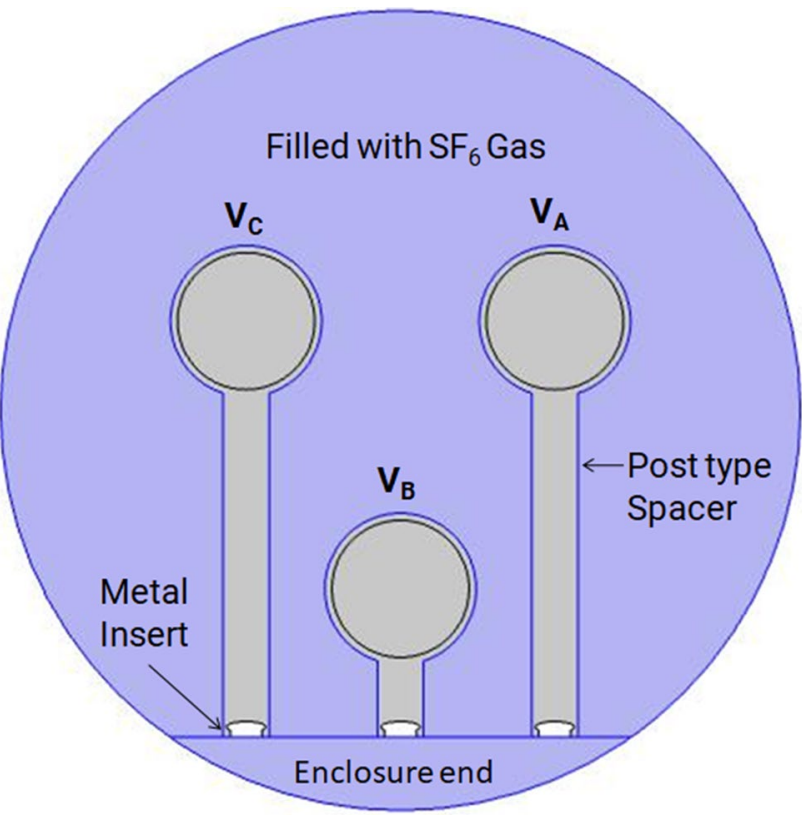

Fig. 6 Representation of post/epoxy type spacer along with MI that the incorporated MI at the enclosure of conductor B has been minimized the developed electric field intensity largely when compared to supplementary conductors. It is observed that for conductor B, electric field intensity is reduced from 0.10645 to 0.007 , which is reduced by a percentage of $93.42 \%$ at $\mathrm{V}_{1}$. Similarly, at $\mathrm{V}_{2}$ the field intensity is minimized from 0.1938 to 0.0127 with a percentage reduction of $93.44 \%$. The field intensity is minimized from 0.323 to 0.0213 with a reduction of $93.40 \%$ at $\mathrm{V}_{3}$. Reduction of the electric field has been shown in Fig. 6 after insertion of MI to epoxy post type spacer. From Fig. 8, the electrical field intensity is minimized drastically for all conductors within a range of 0.005 to $0.03 \mathrm{kV} / \mathrm{cm}$ for different applied voltages.

\subsection{FGM Post Type Spacer Without MI}

The above effects of the spacer style post/epoxy without and with metal insert resulted in the non-uniform distribution of the electric field over the spacer surface of all three conductors. A post-type FGM spacer is equipped with different FGM grades such as GL, GH, and GU-FGM with different permittivity's in different cases in order to create a consistent electrical field distribution. From Table 5, it is observed that GL-FGM grading is comparatively with the high electrical field strength at the TJ's ends of the enclosure for case I

Table 4 Electrical field intensity of post type spacer with metal insert

\begin{tabular}{|c|c|c|c|c|c|c|}
\hline \multirow[t]{2}{*}{ Conductor } & \multicolumn{2}{|l|}{$\mathrm{V}_{1}=72.5 \mathrm{kV}$} & \multicolumn{2}{|l|}{$\mathrm{V}_{2}=132 \mathrm{kV}$} & \multicolumn{2}{|l|}{$\mathrm{V}_{3}=220 \mathrm{kV}$} \\
\hline & $\mathbf{E}_{\text {enclosure }}(\mathrm{kV} / \mathrm{cm})$ & $\mathbf{E}_{\text {conductor }}(\mathrm{kV} / \mathrm{cm})$ & $\mathbf{E}_{\text {enclosure }}(\mathrm{kV} / \mathrm{cm})$ & $\mathbf{E}_{\text {conductor }}(\mathrm{kV} / \mathrm{cm})$ & $\mathbf{E}_{\text {enclosure }}(\mathrm{kV} / \mathrm{cm})$ & $\mathbf{E}_{\text {conductor }}(\mathrm{kV} / \mathrm{cm})$ \\
\hline A & 0.0009 & 0.1693 & 0.0017 & 0.3085 & 0.0028 & 0.5137 \\
\hline B & 0.0099 & 0.1461 & 0.0179 & 0.266 & 0.0299 & 0.4434 \\
\hline $\mathrm{C}$ & 0.00285 & 0.1175 & 0.0051 & 0.214 & 0.00852 & 0.357 \\
\hline
\end{tabular}

Fig. 7 Electrical field distribution of three conductors of post/ epoxy type spacer at different applied voltages

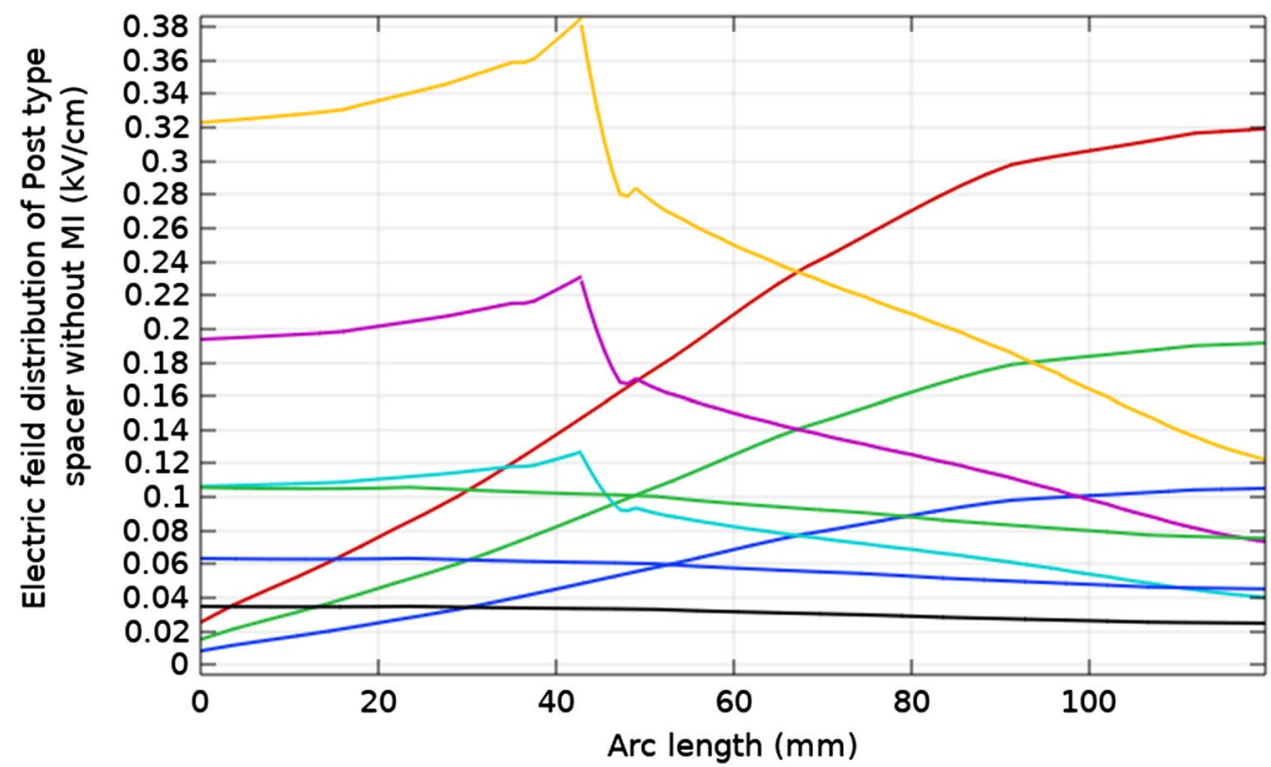




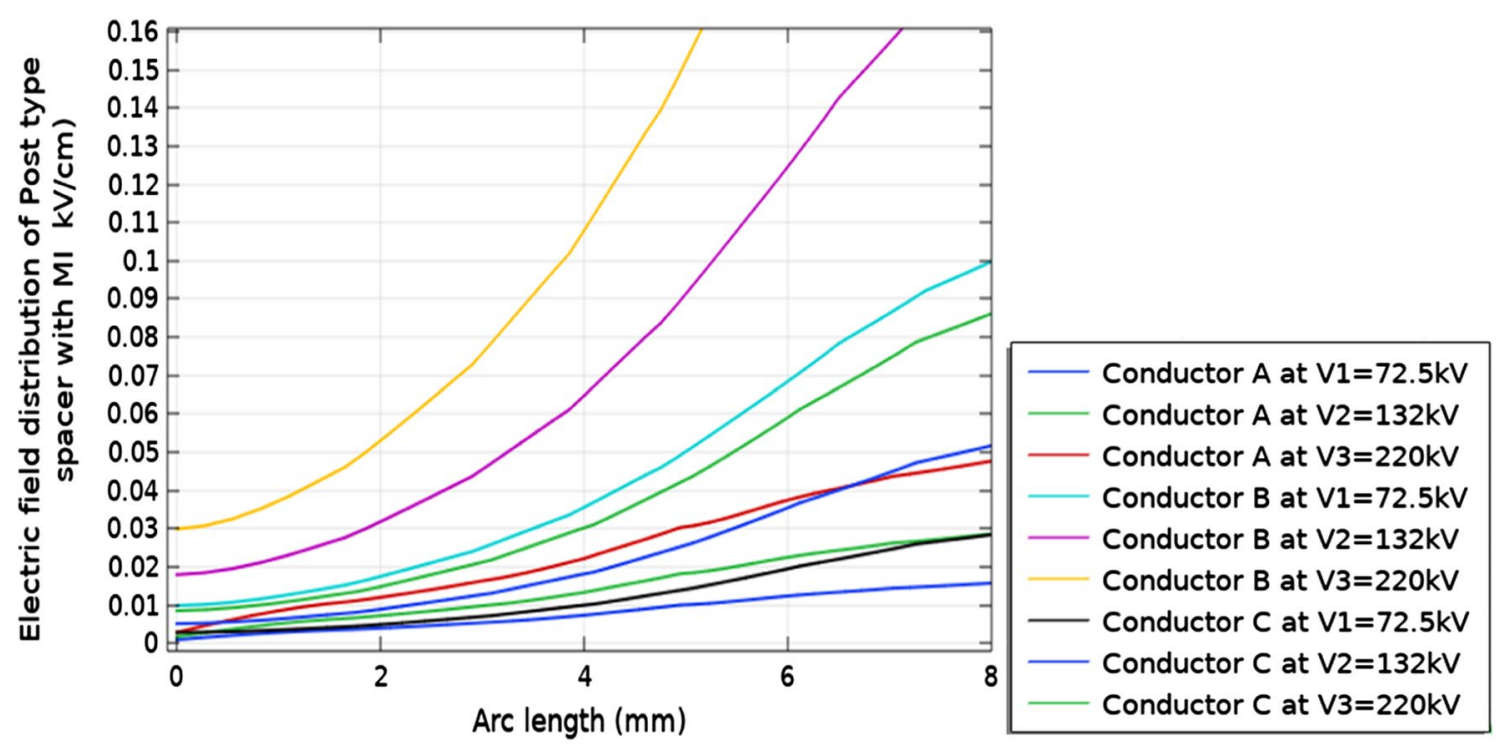

Fig. 8 Electrical Field distribution of three conductors of post/epoxy type spacer with MI at different applied voltages

Table 5 Electrical field intensity of FGM post type spacer without metal insert

\begin{tabular}{|c|c|c|c|c|c|c|c|c|}
\hline \multirow[t]{2}{*}{ Type } & \multirow[t]{2}{*}{ Conductor } & \multirow{2}{*}{$\begin{array}{l}\text { Permittivity } \\
\text { values }\end{array}$} & \multicolumn{2}{|l|}{$\mathrm{V}_{1}=72.5 \mathrm{kV}$} & \multicolumn{2}{|l|}{$\mathrm{V}_{2}=132 \mathrm{kV}$} & \multicolumn{2}{|l|}{$\mathrm{V}_{3}=220 \mathrm{kV}$} \\
\hline & & & $\begin{array}{l}\mathbf{E}_{\text {enclosure }}(\mathrm{kV} / \\
\mathrm{cm})\end{array}$ & $\begin{array}{l}\mathbf{E}_{\text {conductor }}(\mathrm{kV} / \\
\mathrm{cm})\end{array}$ & $\begin{array}{l}\mathbf{E}_{\text {enclosure }}(\mathrm{kV} / \\
\mathrm{cm})\end{array}$ & $\begin{array}{l}\mathbf{E}_{\text {conductor }}(\mathrm{kV} / \\
\mathrm{cm})\end{array}$ & $\begin{array}{l}\mathbf{E}_{\text {enclosure }}(\mathrm{kV} / \\
\mathrm{cm})\end{array}$ & $\begin{array}{l}\mathbf{E}_{\text {conductor }}(\mathrm{kV} / \\
\mathrm{cm})\end{array}$ \\
\hline \multirow[t]{9}{*}{ GL FGM } & \multirow[t]{3}{*}{ A } & Case I & 0.0104 & 0.1682 & 0.019 & 0.3062 & 0.0316 & 0.5105 \\
\hline & & Case II & 0.0108 & 0.1687 & 0.0197 & 0.3072 & 0.0329 & 0.512 \\
\hline & & Case III & 0.0113 & 0.1693 & 0.0205 & 0.3082 & 0.0342 & 0.5138 \\
\hline & \multirow[t]{3}{*}{ B } & Case I & 0.1322 & 0.1445 & 0.2408 & 0.2631 & 0.4013 & 0.4386 \\
\hline & & Case II & 0.1327 & 0.1447 & 0.2417 & 0.2634 & 0.4028 & 0.439 \\
\hline & & Case III & 0.1333 & 0.1449 & 0.2426 & 0.2637 & 0.4044 & 0.4396 \\
\hline & \multirow[t]{3}{*}{$\mathrm{C}$} & Case I & 0.0395 & 0.1178 & 0.0718 & 0.2146 & 0.1197 & 0.3576 \\
\hline & & Case II & 0.0396 & 0.1182 & 0.072 & 0.2153 & 0.12 & 0.3588 \\
\hline & & Case III & 0.0397 & 0.1186 & 0.0722 & 0.2161 & 0.1203 & 0.3601 \\
\hline \multirow[t]{9}{*}{ GH FGM } & \multirow[t]{3}{*}{ A } & Case I & 0.0088 & 0.186 & 0.016 & 0.3385 & 0.0267 & 0.564 \\
\hline & & Case II & 0.009 & 0.1878 & 0.0165 & 0.3418 & 0.0274 & 0.57 \\
\hline & & Case III & 0.0093 & 0.1898 & 0.0169 & 0.3455 & 0.0282 & 0.576 \\
\hline & \multirow[t]{3}{*}{ B } & Case I & 0.0843 & 0.1486 & 0.1534 & 0.2706 & 0.2557 & 0.4511 \\
\hline & & Case II & 0.0837 & 0.1491 & 0.1523 & 0.2715 & 0.2539 & 0.4524 \\
\hline & & Case III & 0.0831 & 0.1496 & 0.1512 & 0.2724 & 0.252 & 0.454 \\
\hline & \multirow[t]{3}{*}{$\mathrm{C}$} & Case I & 0.0317 & 0.1331 & 0.0577 & 0.238 & 0.0962 & 0.3964 \\
\hline & & Case II & 0.03168 & 0.1318 & 0.0577 & 0.24 & 0.0961 & 0.4001 \\
\hline & & Case III & 0.0316 & 0.1306 & 0.0576 & 0.2425 & 0.096 & 0.404 \\
\hline \multirow[t]{9}{*}{ GU FGM } & \multirow[t]{3}{*}{ A } & Case I & 0.0076 & 0.1681 & 0.0139 & 0.3062 & 0.0231 & 0.5102 \\
\hline & & Case II & 0.0079 & 0.1687 & 0.0144 & 0.3072 & 0.0239 & 0.512 \\
\hline & & Case III & 0.0081 & 0.1693 & 0.0149 & 0.3082 & 0.0248 & 0.5136 \\
\hline & \multirow[t]{3}{*}{ B } & Case I & 0.0975 & 0.1449 & 0.1775 & 0.2637 & 0.2958 & 0.4396 \\
\hline & & Case II & 0.0972 & 0.1447 & 0.177 & 0.2635 & 0.295 & 0.4392 \\
\hline & & Case III & 0.0969 & 0.1446 & 0.1764 & 0.2632 & 0.294 & 0.4387 \\
\hline & \multirow[t]{3}{*}{$\mathrm{C}$} & Case I & 0.03301 & 0.1179 & 0.06011 & 0.2146 & 0.10019 & 0.3578 \\
\hline & & Case II & 0.03302 & 0.1183 & 0.06015 & 0.2154 & 0.10025 & 0.359 \\
\hline & & Case III & 0.03304 & 0.1187 & 0.06018 & 0.2161 & 0.10032 & 0.3578 \\
\hline
\end{tabular}


for conductor A and C and for case III for conductor B for all three applied voltages of $\mathrm{V}_{1}, \mathrm{~V}_{2}$, and $\mathrm{V}_{3}$. The electrical field intensity at conductor $\mathrm{A}$ is noticed high because of the maximum applied voltage to the conductor A comparatively as from Table 1. From Table 5, it is identified that the field stress is very high at TJ's for all three FGM gradings. For GL-FGM at $72.5 \mathrm{kV}$ operating voltage of conductor A, the electrical field intensity is $0.0104 \mathrm{kV} / \mathrm{cm}$ in case I. Similarly, for case II the electrical field intensity is $0.0108 \mathrm{kV} / \mathrm{cm}$ and for case III it is $0.0113 \mathrm{kV} / \mathrm{cm}$. However, for conductor B at $\mathrm{V}_{1}=72.5 \mathrm{kV}$, the electric field intensity is $0.1322 \mathrm{kV} /$ $\mathrm{cm}$ in case I. Similarly, for case II the electrical field intensity is $0.1327 \mathrm{kV} / \mathrm{cm}$ and for case III it is $0.1333 \mathrm{kV} / \mathrm{cm}$.
Similarly, for conductor $\mathrm{C}$ at $\mathrm{V}_{1}=72.5 \mathrm{kV}$, the electrical field intensity is $0.0395 \mathrm{kV} / \mathrm{cm}$ in case I. Similarly, for case II the electric field intensity is $0.0396 \mathrm{kV} / \mathrm{cm}$ and for case III it is $0.0397 \mathrm{kV} / \mathrm{cm}$. From Table 5, it is noticed that electric field intensity at the enclosure and conductor ends has been increased as the operating voltage increases. Similarly, for GH and GU-FGM gradings, the values of electric field intensity have observed from the table. The variation of electrical field intensity of three conductors of FGM post type spacer with respect to arc length is shown in Figs. 9, 10 and 11 respectively. From Fig. 9, the electrical field intensity is observed from 0.01 to $0.0316 \mathrm{kV} / \mathrm{cm}$ for $\mathrm{V}_{1}, \mathrm{~V}_{2}$ and $\mathrm{V}_{3}$ which is high at the enclosure end which may lead to
Fig. 9 Electrical field distribution of conductor A of post type FGM spacer at different applied voltages
Fig. 10 Electrical field distribution of conductor B of post type FGM spacer at different applied voltages
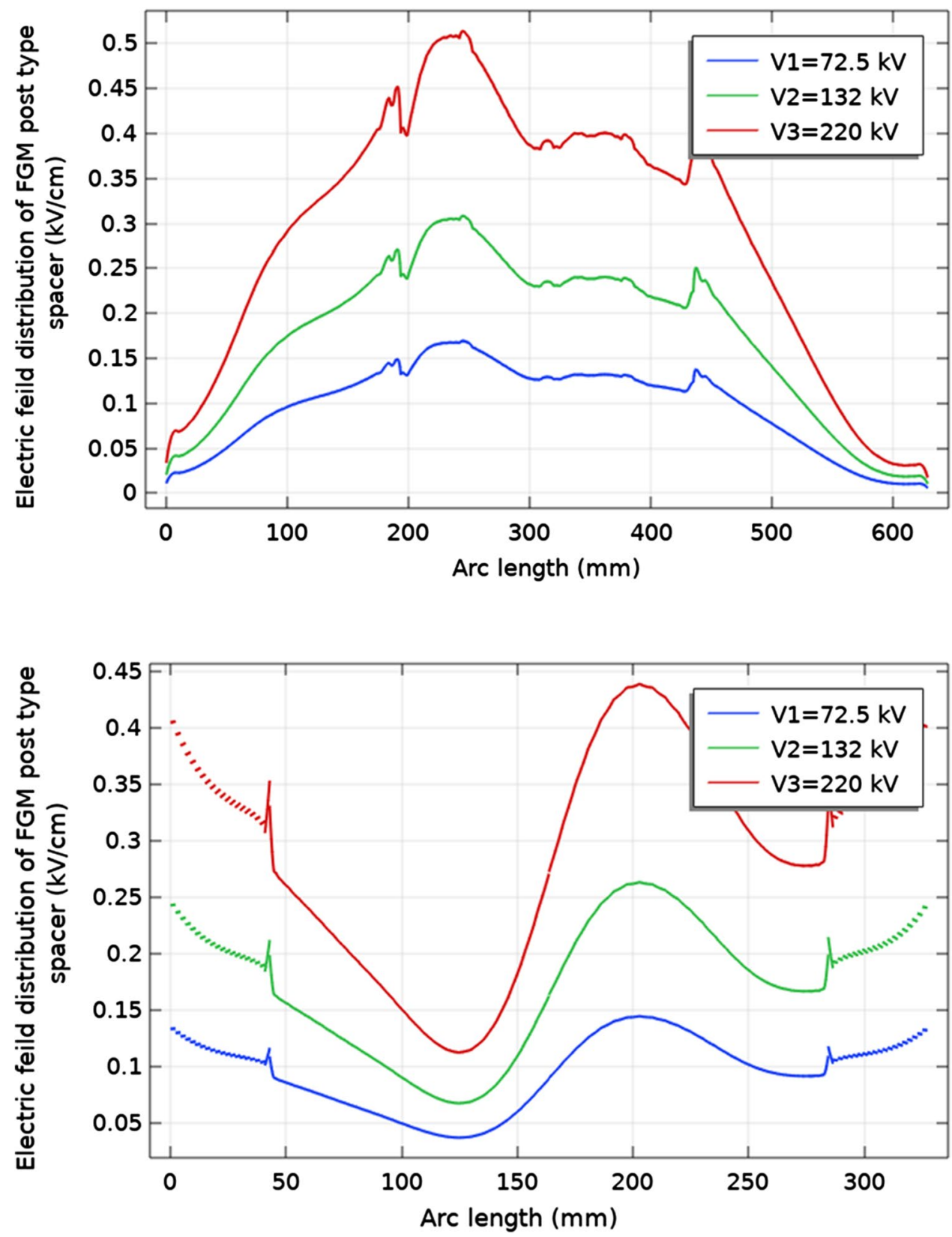
Fig. 11 Electrical field distribution of conductor $\mathrm{C}$ of post type FGM spacer at different applied voltages
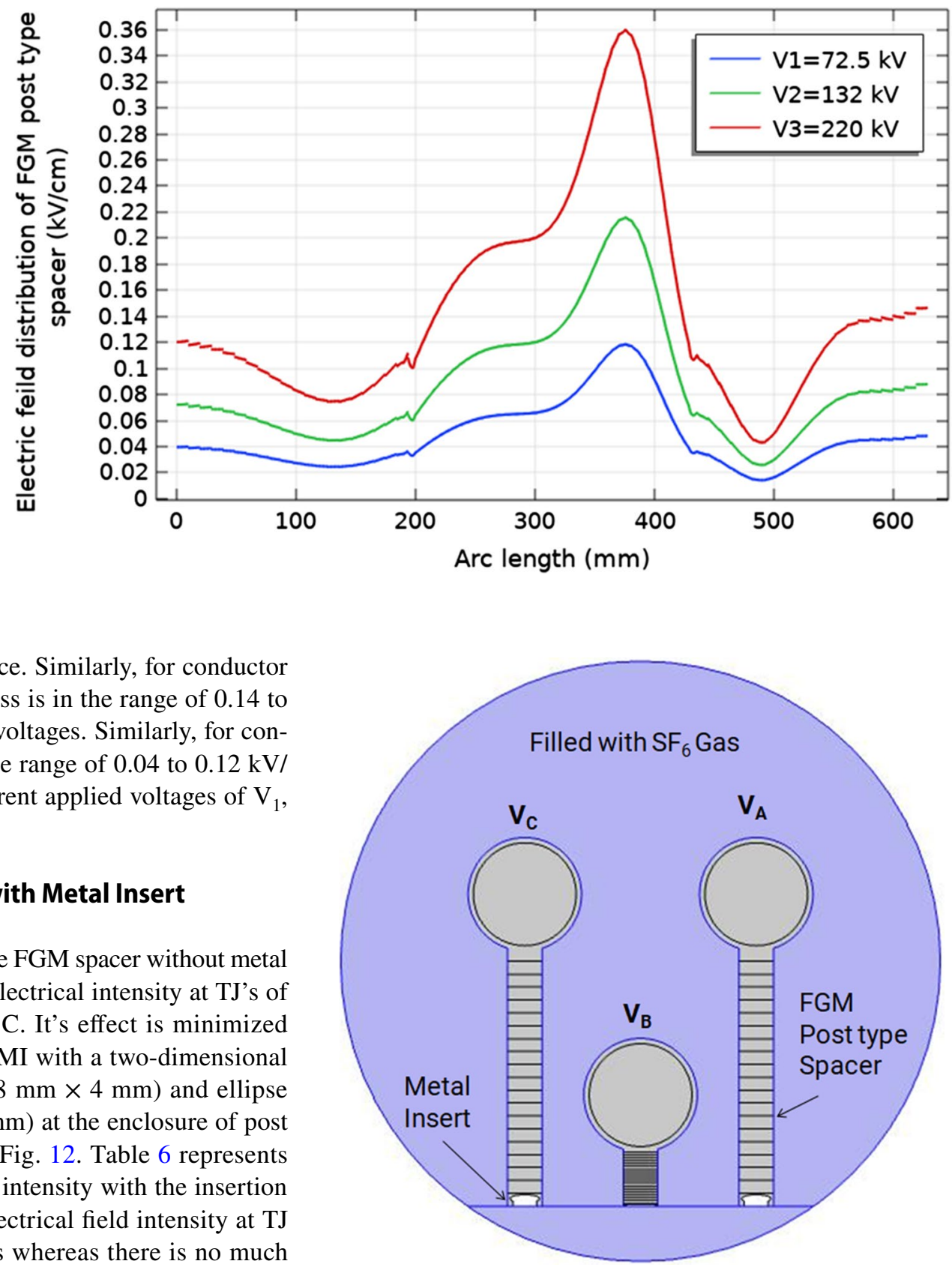

failure of the spacer performance. Similarly, for conductor $\mathrm{B}$ as from Fig. 10, the field stress is in the range of 0.14 to $0.4 \mathrm{kV} / \mathrm{cm}$ at different applied voltages. Similarly, for conductor $\mathrm{C}$ the field stress is in the range of 0.04 to $0.12 \mathrm{kV} /$ $\mathrm{cm}$ as shown in Fig. 11 at different applied voltages of $\mathrm{V}_{1}$, $\mathrm{V}_{2}$ and $\mathrm{V}_{3}$.

\subsection{FGM Post Type Spacer with Metal Insert}

The results of the above post type FGM spacer without metal insert has resulted in the high electrical intensity at TJ's of all three conductors A, B and C. It's effect is minimized by designing a recessed metal $\mathrm{MI}$ with a two-dimensional combination of rectangular $(18 \mathrm{~mm} \times 4 \mathrm{~mm})$ and ellipse (a-axis of $11 \mathrm{~mm}, \mathrm{~b}$-axis of $3 \mathrm{~mm}$ ) at the enclosure of post type FGM spacer as shown in Fig. 12. Table 6 represents the reduction of electrical field intensity with the insertion of MI, from this Table 6 the electrical field intensity at TJ is reduced for three conductors whereas there is no much reduction of electrical field intensity at the conductor ends as there is no impact of MI at this end for a three phase GIB. From Table 6 the maximum reduction is obtained in GU-FGM grading, hence further the analysis is done for conductor B of GH and GU-FGM gradings. For conductor $B$ at the case I of GL grading, the electrical field intensity is reduced from 0.1322 to $0.0269 \mathrm{kV} / \mathrm{cm}$, which is reduced by a percentage of $79.65 \%$ at $\mathrm{V}_{1}$. At $\mathrm{V}_{2}$, the field stress is minimized from 0.2408 to $0.049 \mathrm{kV} / \mathrm{cm}$ with a minimization of $79.65 \%$. At $\mathrm{V}_{3}$, the field stress is minimized from 0.4013 to $0.082 \mathrm{kV} / \mathrm{cm}$ with minimization of $79.57 \%$. Similarly, at $\mathrm{V}_{1}$ the percentage reduction of $79.13 \%$ and $78.62 \%$ is observed for case II and case III respectively. For conductor $\mathrm{B}$ at the case I of GH grading, the electrical field intensity
Fig. 12 Representation of post type FGM spacer with MI

is reduced from 0.0843 to $0.001295 \mathrm{kV} / \mathrm{cm}$ which is minimized by a percentage of $98.46 \%$ at $\mathrm{V}_{1}$. At $\mathrm{V}_{2}$ the field stress is reduced from 0.1534 to $0.02355 \mathrm{kV} / \mathrm{cm}$ with minimization of $84.65 \%$. At $\mathrm{V}_{3}$ the field stress is reduced from 0.2557 to $0.03925 \mathrm{kV} / \mathrm{cm}$ with minimization of $84.65 \%$. Similarly, at $\mathrm{V}_{1}$ the percentage minimization of $98.44 \%$ and $98.42 \%$ is observed for case II and case III respectively. For conductor B at the case I of GU-FGM grading, the electrical field intensity is minimized from 0.0975 to $0.001498 \mathrm{kV} / \mathrm{cm}$, which is minimized by a percentage of $98.46 \%$ at $\mathrm{V}_{1}$. At 
Table 6 Electrical field intensity of post type FGM spacer with metal insert

\begin{tabular}{|c|c|c|c|c|c|c|c|c|}
\hline \multirow[t]{2}{*}{ Type } & \multirow[t]{2}{*}{ Conductor } & \multirow{2}{*}{$\begin{array}{l}\text { Permittivity } \\
\text { values }\end{array}$} & \multicolumn{2}{|l|}{$\mathrm{V}_{1}=72.5 \mathrm{kV}$} & \multicolumn{2}{|l|}{$\mathrm{V}_{2}=132 \mathrm{kV}$} & \multicolumn{2}{|l|}{$\mathrm{V}_{3}=220 \mathrm{kV}$} \\
\hline & & & $\begin{array}{l}\mathbf{E}_{\text {enclosure }}(\mathrm{kV} / \\
\mathrm{cm})\end{array}$ & $\begin{array}{l}\mathbf{E}_{\text {conductor }}(\mathrm{kV} / \\
\mathrm{cm})\end{array}$ & $\begin{array}{l}\mathbf{E}_{\text {enclosure }}(\mathrm{kV} / \\
\mathrm{cm})\end{array}$ & $\begin{array}{l}\mathbf{E}_{\text {conductor }}(\mathrm{kV} / \\
\mathrm{cm})\end{array}$ & $\begin{array}{l}\mathbf{E}_{\text {enclosure }}(\mathrm{kV} / \\
\mathrm{cm})\end{array}$ & $\begin{array}{l}\mathbf{E}_{\text {conductor }}(\mathrm{kV} / \\
\mathrm{cm})\end{array}$ \\
\hline \multirow[t]{9}{*}{ GL-FGM } & \multirow[t]{3}{*}{ A } & Case I & 0.0019 & 0.1682 & 0.0036 & 0.3062 & 0.006 & 0.5105 \\
\hline & & Case II & 0.0021 & 0.1687 & 0.0038 & 0.3072 & 0.0064 & 0.512 \\
\hline & & Case III & 0.0022 & 0.1693 & 0.004 & 0.3082 & 0.0067 & 0.514 \\
\hline & \multirow[t]{3}{*}{ B } & Case I & 0.0269 & 0.145 & 0.049 & 0.264 & 0.082 & 0.4401 \\
\hline & & Case II & 0.0277 & 0.1449 & 0.05 & 0.2637 & 0.084 & 0.4396 \\
\hline & & Case III & 0.0285 & 0.1447 & 0.052 & 0.2635 & 0.0865 & 0.4391 \\
\hline & \multirow[t]{3}{*}{$\mathrm{C}$} & Case I & 0.0049 & 0.1178 & 0.009 & 0.2146 & 0.015 & 0.3575 \\
\hline & & Case II & 0.0051 & 0.1182 & 0.0093 & 0.2152 & 0.0155 & 0.359 \\
\hline & & Case III & 0.0053 & 0.1186 & 0.0096 & 0.216 & 0.0161 & 0.36 \\
\hline \multirow[t]{9}{*}{ GH-FGM } & \multirow[t]{3}{*}{ A } & Case I & 0.0011 & 0.187 & 0.00209 & 0.3405 & 0.00348 & 0.568 \\
\hline & & Case II & 0.00115 & 0.189 & 0.00215 & 0.344 & 0.00358 & 0.573 \\
\hline & & Case III & 0.00125 & 0.191 & 0.00222 & 0.3475 & 0.0037 & 0.5785 \\
\hline & \multirow[t]{3}{*}{ B } & Case I & 0.001295 & 0.1489 & 0.02355 & 0.2719 & 0.03925 & 0.4518 \\
\hline & & Case II & 0.001302 & 0.1494 & 0.0237 & 0.2719 & 0.0395 & 0.4532 \\
\hline & & Case III & 0.00131 & 0.1499 & 0.02389 & 0.2729 & 0.0397 & 0.4548 \\
\hline & \multirow[t]{3}{*}{$\mathrm{C}$} & Case I & 0.002602 & 0.1306 & 0.00479 & 0.238 & 0.00805 & 0.3965 \\
\hline & & Case II & 0.002606 & 0.1318 & 0.00488 & 0.24 & 0.0081 & 0.4 \\
\hline & & Case III & 0.002702 & 0.1311 & 0.00495 & 0.2425 & 0.0082 & 0.404 \\
\hline \multirow[t]{9}{*}{ GU-FGM } & \multirow[t]{3}{*}{ A } & Case I & 0.00108 & 0.1681 & 0.00198 & 0.3062 & 0.00328 & 0.5105 \\
\hline & & Case II & 0.00112 & 0.1687 & 0.00208 & 0.3072 & 0.0034 & 0.512 \\
\hline & & Case III & 0.00118 & 0.1693 & 0.0021 & 0.3082 & 0.00352 & 0.5138 \\
\hline & \multirow[t]{3}{*}{ B } & Case I & 0.001498 & 0.14475 & 0.0272 & 0.26355 & 0.00454 & 0.4392 \\
\hline & & Case II & 0.00151 & 0.14488 & 0.0275 & 0.26378 & 0.04588 & 0.4396 \\
\hline & & Case III & 0.001528 & 0.1452 & 0.0278 & 0.2644 & 0.0463 & 0.4401 \\
\hline & \multirow[t]{3}{*}{$\mathrm{C}$} & Case I & 0.00275 & 0.1179 & 0.00498 & 0.2161 & 0.00832 & 0.3578 \\
\hline & & Case II & 0.00278 & 0.1183 & 0.00508 & 0.2154 & 0.00848 & 0.359 \\
\hline & & Case III & 0.00285 & 0.1187 & 0.00518 & 0.2146 & 0.00862 & 0.3602 \\
\hline
\end{tabular}

$\mathrm{V}_{2}$ the field stress is minimized from 0.1775 to $0.0272 \mathrm{kV} /$ $\mathrm{cm}$ with minimization of $84.68 \%$. At $\mathrm{V}_{3}$ the field stress is reduced from 0.2958 to $0.00454 \mathrm{kV} / \mathrm{cm}$ with minimization of $98.47 \%$. Similarly, at $\mathrm{V}_{1}$ the percentage reduction of $98.45 \%$ and $98.42 \%$ is noticed for case II and case III respectively. From Figs. 9, 10 and 11, it is noticed that magnitude of electric field intensity at the enclosure is maximum for all the three conductors. This high electrical field intensity is further minimized by inserting MI's at the enclosure ends of all the three FGM post type spacer with MI are shown for three conductors in the corresponding Figs. 13, 14 and 15. By comparing Figs. 9 and 13, the electrical field intensity is reduced drastically at TJ of the enclosure end. Similarly, maximum minimization is obtained for conductors $\mathrm{B}$ and $\mathrm{C}$ as shown in Figs. 14 and 15 respectively.

Figure 16 represents the surface plots with height as a dimension for post type FGM spacer of a three phase GIB without MI and Fig. 17 represents the same in the presence of MI. In Fig. 16, the electric field lines are in congestion near the enclosure ends whereas after inserting MI, the congestion of these electric lines has been reduced which as observed from Fig. 17. The corresponding surface plot without its height dimension of Figs. 16, 17 is shown in Figs. 18 and 19 respectively. The contour plots of the FGM post form spacer without and with conductor B MI are shown in Figs. 20, 21 respectively, in order to provide a better understanding of the distribution of electrical field. From Fig. 21, the electric field intensity is reduced at the enclosure than that of Fig. 20. Similarly, the electrical field intensity of FGM post type spacer with MI can be noticed from mesh plot indicating less thickness of the mesh triangles in Fig. 22 when compared to mesh plot without MI as shown in Fig. 23. 
Fig. 13 Electrical field distribution of conductor A of post type FGM spacer with MI at different applied voltages
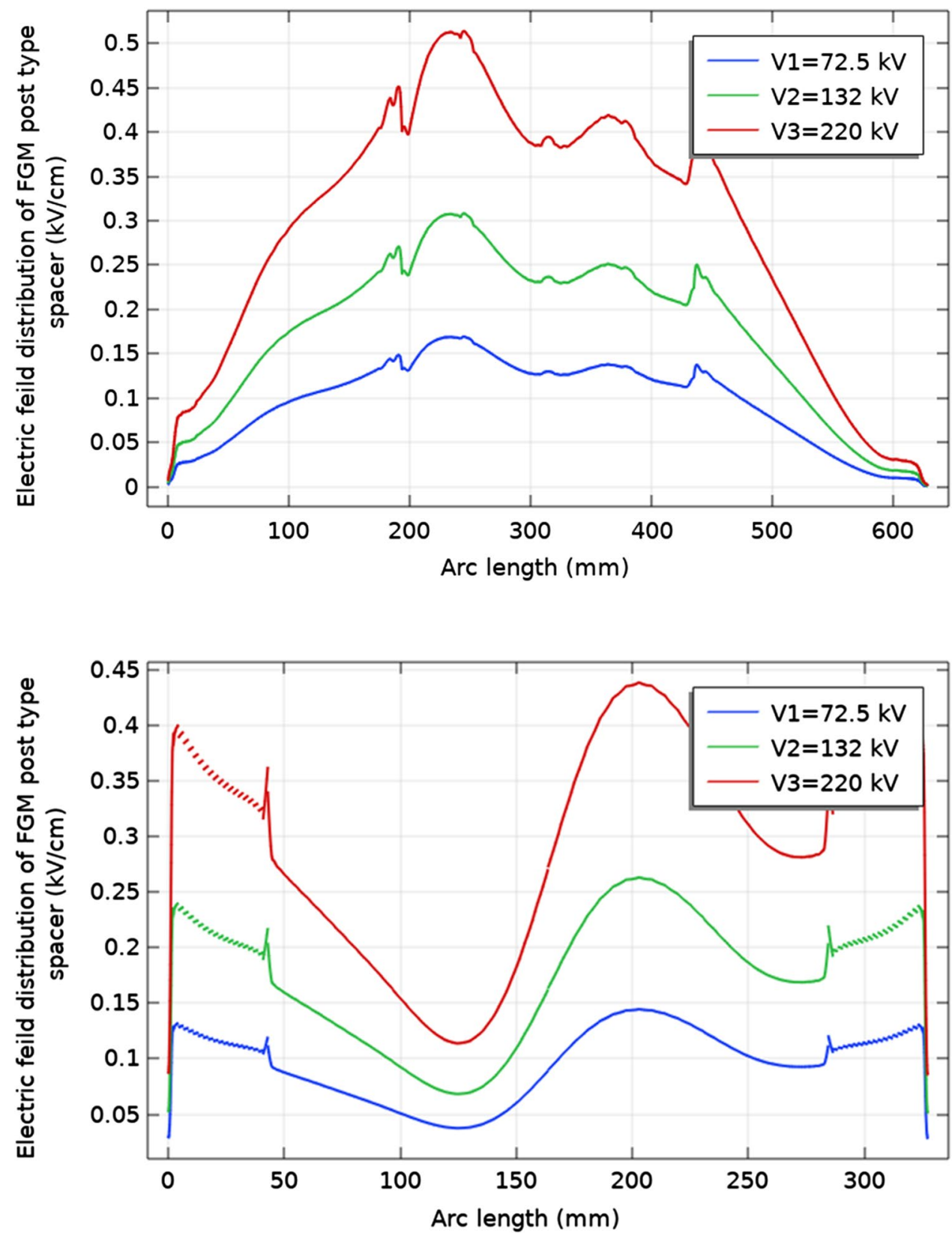

Fig. 14 Electrical field distribution of conductor B of post type FGM spacer with MI at different applied voltages

\section{Conclusion}

In this paper, the three-phase GIB with post/ epoxy type the spacer is simulated, using finite element method. The electric field distribution is obtained at both the enclosure and conductor ends of all the three post type spacers enclosed inside the GIB. By taking the highest electric field intensity of post type spacer into consideration, metal inserts have been inserted at the enclosure ends for all the three spacers. This highest electric field is reduced drastically for all conductors after inserting MI for different applied voltages. The main purpose of this paper is to introduce the FGM technique to the three-phase GIB to create a uniform electrical field intensity over the spacer at different applied voltages. Three different gradings like GL, GH, and GU-FGM are taken for the study of the effectiveness with specific dielectric permittivity ranges and from the results, the following conclusions were made:

- Comparatively the conductor ends has resulted in a high electric field intensity than the enclosure ends for all the three conductors.

- The obtained electrical field intensity is more at conductor end of conductor A than other two conductors at different applied voltages. 
Fig. 15 Electrical field distribution of conductor $\mathrm{C}$ of post type FGM spacer with MI at different applied voltages
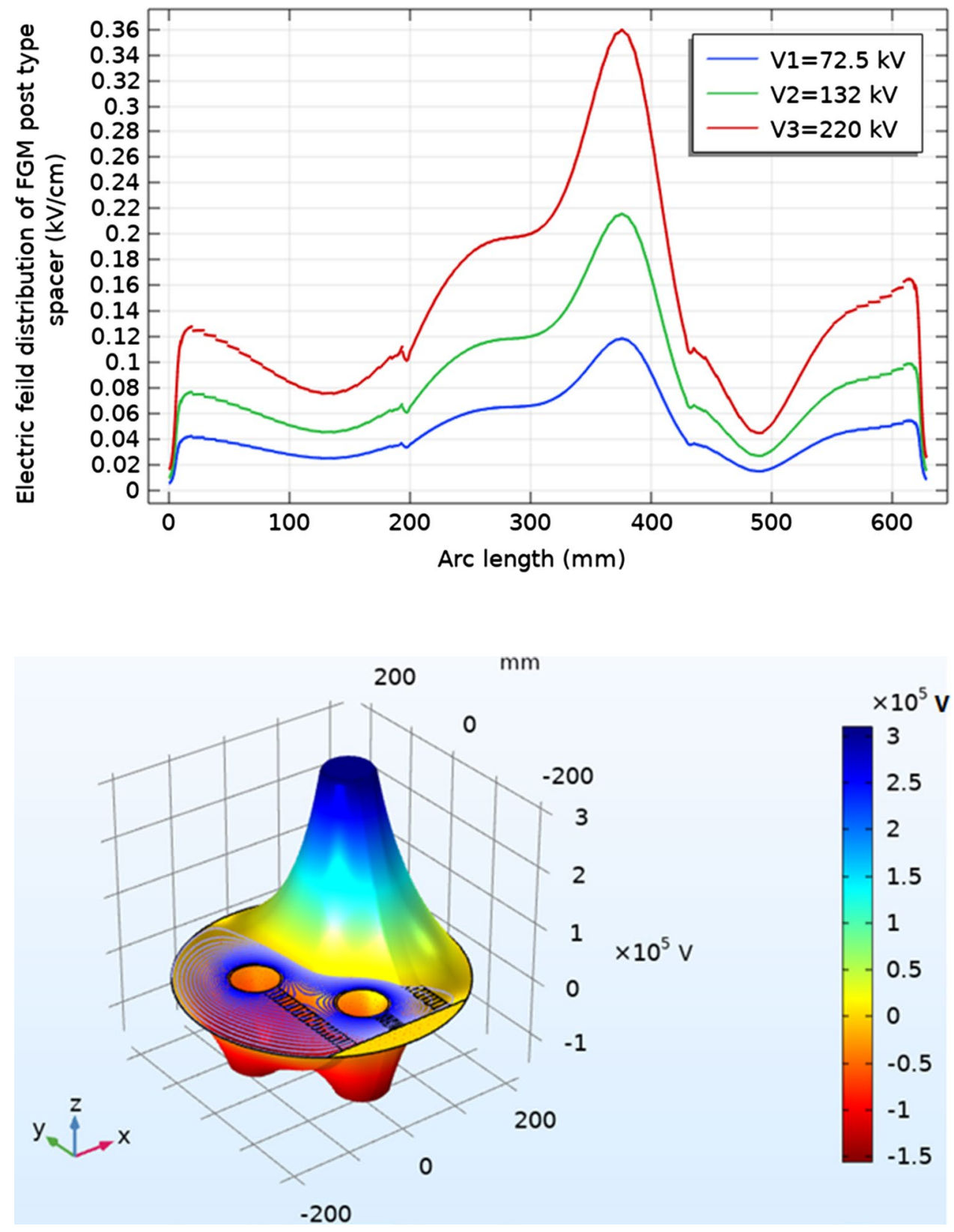

Fig. 16 FGM spacer surface plot with its height
- Due to the weakest link at enclosure end, the electric field distribution is to be concentrated at $\mathrm{TJ}$ and identified that it rises with the rise in operating voltage.

- It is noticed that electric field intensity is high at $\mathrm{TJ}$ for conductor B than other conductors for GL, GH and GUFGM gradings.
- In the absence of metal inserts, metal inserts are used to minimize the electrical field strength and are limited to a value greater than their values.

- From the study of the three separate FGM gradings, GLFGM has enhanced the reduction of the electrical field with the insertion of the metal inserts for a three-phase GIB to post form FGM spacer. 
Fig. 17 FGM spacer surface plot with MI

Fig. 18 Post FGM spacer surface plot
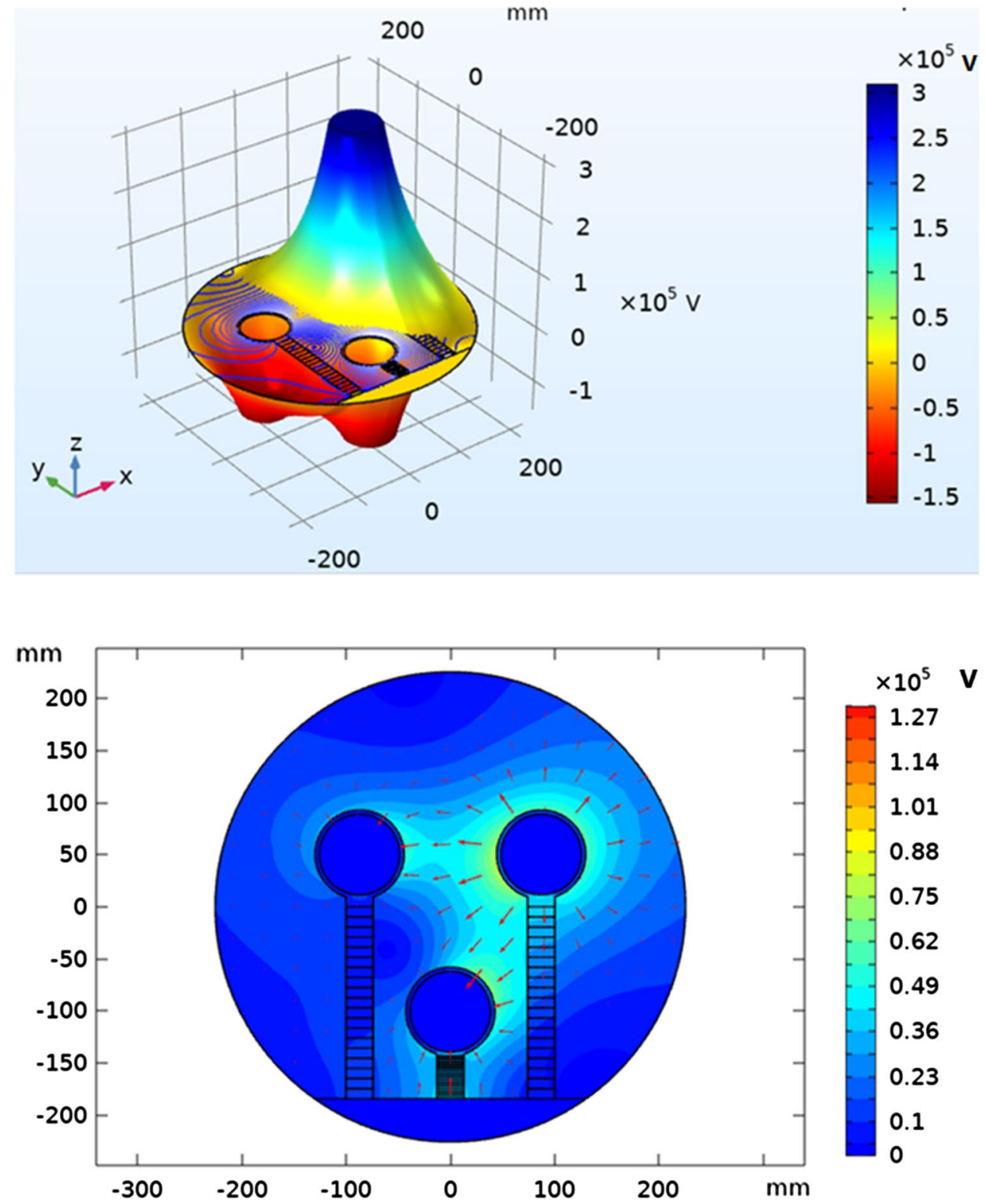
Fig. 19 Post FGM spacer surface plot with MI

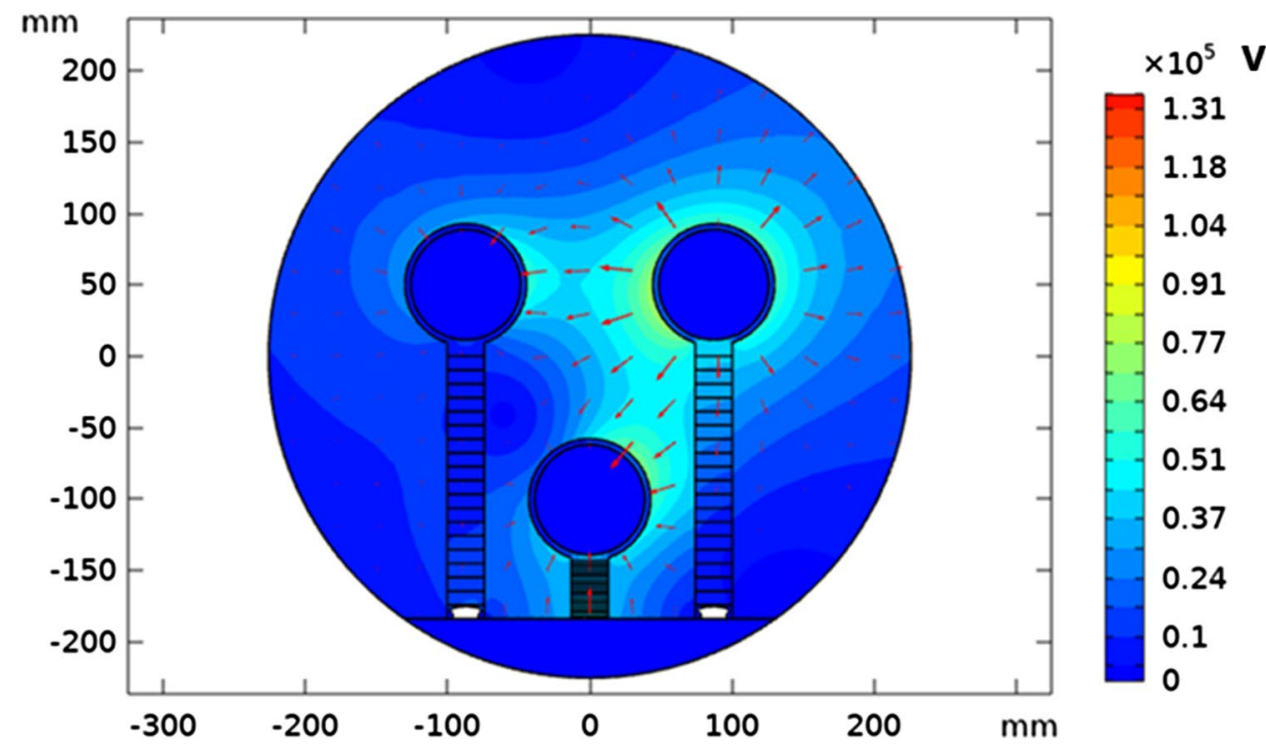

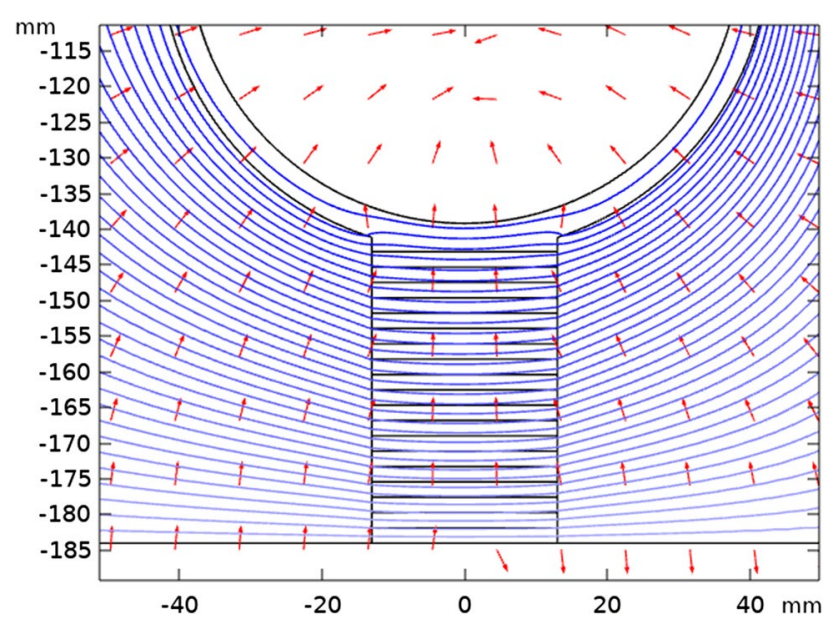

Fig. 20 Post FGM spacer contour plot

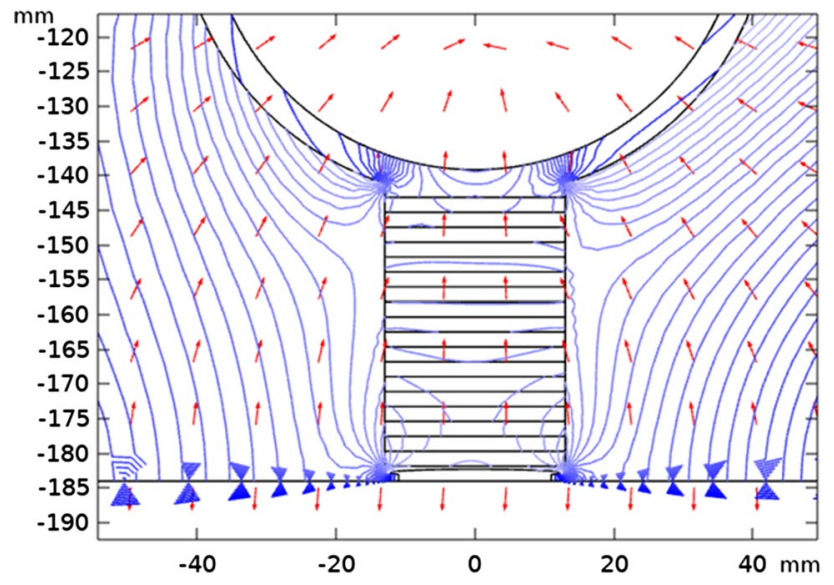

Fig. 21 Post FGM spacer contour plot with MI

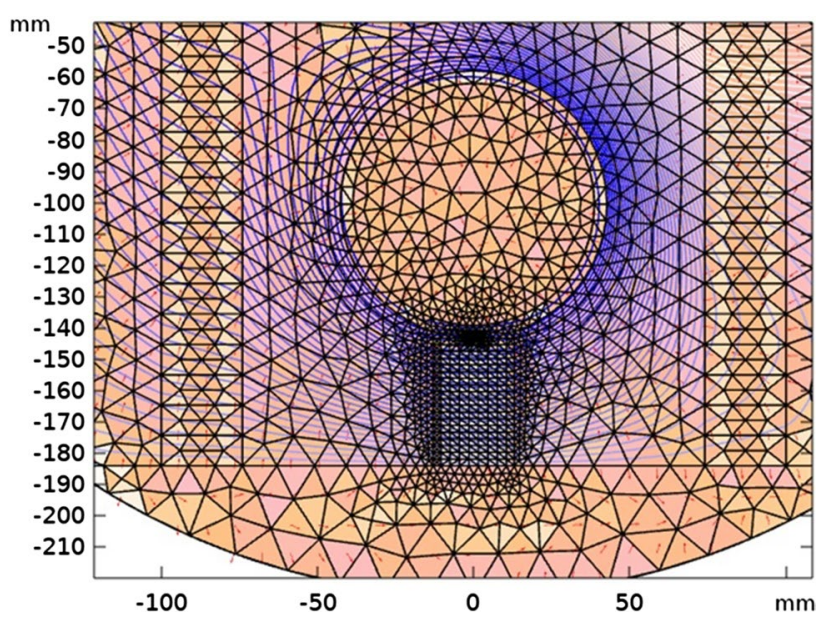

Fig. 22 Post FGM Spacer mesh plot without MI

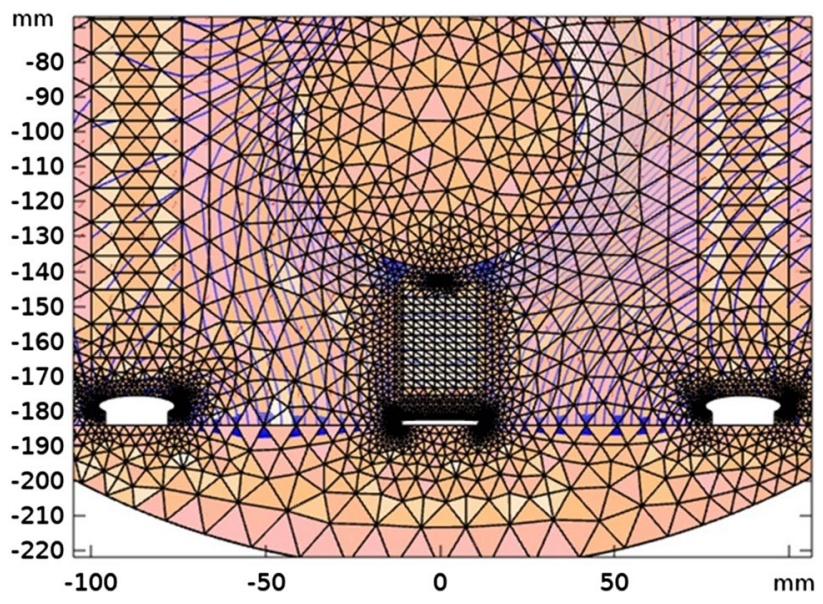

Fig. 23 Post FGM spacer mesh plot with MI 
Open Access This article is licensed under a Creative Commons Attribution 4.0 International License, which permits use, sharing, adaptation, distribution and reproduction in any medium or format, as long as you give appropriate credit to the original author(s) and the source, provide a link to the Creative Commons licence, and indicate if changes were made. The images or other third party material in this article are included in the article's Creative Commons licence, unless indicated otherwise in a credit line to the material. If material is not included in the article's Creative Commons licence and your intended use is not permitted by statutory regulation or exceeds the permitted use, you will need to obtain permission directly from the copyright holder. To view a copy of this licence, visit http://creativecommons.org/licenses/by/4.0/.

\section{References}

1. He C, Zhang L, Li J, Zhang Q, Yao X (2019) Effect of AC and switching impulse superimposed voltage on PD characteristics in SF6 gas. IEEE Trans Dielectr Electr Insulat 26(5):1394-1402

2. Nakano Y, Kozako M, Hikita M, Tanaka T, Kobayashi M (2019) Estimation method of degraded vacuum in vacuum interrupter based on partial discharge measurement. IEEE Trans Dielectr Electr Insulat 26(5):1520-1526

3. Wen T, Zhang Q, Ma J, Wu Z, Shimomura N, Chen W (2019) A new method to evaluate the effectiveness of impulse voltage for detecting insulation defects in GIS equipment. IEEE Trans Dielectr Electr Insulat 26(4):1301-1307

4. Nagesh Kumar GV, Amarnath J, Singh BP, Srivastava KD (2007) Electric field effect on metallic particle contamination in a common enclosure gas insulated busduct. IEEE Trans Dielectr Electr Insulat 14(2):334-340

5. Arbutina D, Stankovic K, Perazic L, Pejovic M (2019) Influence of the shape, number, position and dimensions of conductive particles within inter-electrode gap on DC and pulse breakdown voltage value of SF6 and N2 mixture. Int J Electr Power Energy Syst 104:436-442

6. Talaat M, El-Zein A, Amin M (2018) Electric field simulation for uniform and FGM cone type spacer with adhering spherical conducting particle in GIS. IEEE Trans Dielectr Electr Insulat 25(1):339-351

7. Guo Z, Wu Z, Wang H, Tian H, Liu L, Peng Z, Li H, Wang Q (2019) Experimental and numerical study on formation of interface separation and interfacial dielectric strength of GIL insulator. IEEE Trans Dielectr Electr Insulat 26(6):1738-1746

8. Li C, Lin C, Zhang B, Li Q, Liu W, Hu J, He J (2018) Understanding surface charge accumulation and surface flashover on spacers in compressed gas insulation. IEEE Trans Dielectr Electr Insulat 25(4):1152-1166

9. Wu Z, Zhang Q, Ma J, Li X, Wen T (2018) Effectiveness of onsite dielectric test of GIS equipment. IEEE Trans Dielectr Electr Insulat 25(4):1454-1460

10. Liu X, Zhang L, Wen T, Zhang Q (2018) Influence of spike defect on the impulse breakdown characteristics of SF6 gas gap in GIS. IEEE Trans Dielectr Electr Insulat 25(4):1413-1420

11. Muneaki K, Katsumi K, Masahiro H (2010) Yoshikazu Hoshina, Masafumi Takei, Hitoshi Okubo, Application of functionally graded material for reducing electric field on electrode and spacer interface. IEEE Trans Dielectr Electr Insulat 17(1):256-263

12. Du BX, Liang HC, Li J (2019) Surface coating affecting charge distribution and flashover voltage of cone-type insulator under DC stress. IEEE Trans Dielectr Electr Insulat 26(3):706-713

13. Heung-Jin Ju, Ko K-C, Kim D-K (2013) Optimization of a grounded electrode shape in gas insulated switchgear with a reversely elliptical permittivity graded insulator. IEEE Trans Dielectr Electr Insulat 20(5):1749-1754
14. Hayakawa N, Ishiguro J, Kojima H, Kato K, Okubo H (2016) Fabrication and simulation of permittivity graded materials for electric field grading of gas insulated power apparatus. IEEE Trans Dielectr Electr Insulat 23(1):547-554

15. Hayakawa N, Miyaji Y, Kojima H, Kato K (2018) Simulation on discharge inception voltage improvement of GIS spacer with permittivity graded materials. IEEE Trans Dielectr Electr Insulat 25(4):1318-1323

16. Ran Z, Boxue Du, Li J, Liang H, Kong X, Jiang J, Wang M (2019) Electric field regulation of insulator interface by FGM with conductivity for superconducting-GIL. IEEE Trans Appl Supercond 29(2):1-5

17. An Z, Yang W, Xing Z, Chen W, Chen K, Gao W, Shen Z, Yang Y, Liu F, Liu X, Zhang Z (2020) Comparative study on direct fluorination and surface properties of alumina-filled and unfilled epoxy insulators. IEEE Trans Dielectr Electr Insulat 27(1):85-93

18. Liu L, Li X, Wen T, Zhang R, Wu Z, Zhao J, Zhang Q (2019) Investigation on surface electric field distribution features related to insulator flashover in SF6 gas. IEEE Trans Dielectr Electr Insulat 26(5):1588-1595

19. Chakravorti S (2004) A Lahiri, Electrode-spacer contour optimization by ANN aided genetic algorithm. IEEE Trans Dielectr Electr Insulat 11(6):964-975

20. Farish I, Bawy AI (1991) Effect of surface charge on impulseflashover of insulators in SF6. IEEE Trans Electr Insulat 26(3):443-452

21. Deepak Chowdary D, Amarnath J (2011) Electric field analysis at the triple junction of a optimum profile disc type spacer in SF6 gas insulated system with abnormalities under DC voltages. In: IEEE Annual Report Conference, pp 215-218

22. Imai T, Hoshina Y, Kojima H, Hayakawa N (2019) Resin injection behavior in process of manufacturing insulation spacer with permittivity gradient using computational fluid dynamics. IEEE Trans Dielectr Electr Insulat 26(5):1669-1677

23. Imai T, Takeuchi M, Hoshina Y, Kojima H, Hayakawa N (2019) Comparison of permittivity gradient in resin injected and simulated cone-shaped spacers. IEEE Trans Dielectr Electr Insulat 26(5):1678-1685

24. Du BX, Wang ZH, Li J, Liang HC, Li ZH (2020) Epoxy insulator with surface graded-permittivity by magnetron sputtering for gasinsulated line. IEEE Trans Dielectr Electr Insulat 27(1):197-205

25. Du BX, Liang HC, Li J (2020) Novel spacer coated with functionally graded $\mathrm{ZnO}$ film for HVDC gas insulated line. IEEE Trans Dielectr Electr Insulat 27(1):231-239

26. Kurimoto M, Ozaki H, Sawada T, Funabashi T, Kato T, Suzuoki Y (2018) FEM simulation of local field enhancement close to lamination interface of permittivity-graded material. Electr Eng Jpn IEEJ Trans Electr Electron Eng 101(6):1-87

27. Straumann U, Stoller PC (2019) The impact of partly liquefied SF6 on the dielectric performance of SF6-insulated switchgear. IEEE Trans Dielectr Electr Insulat 26(1):137-145

28. Zhang JW, Gao FK, Cao DK, Putson C, Song C, Chen W, Zhang $\mathrm{J}$ (2018) Modeling of charge transport in insulating dielectric for gas-insulated transmission line based on multiple trap levels. IEEE Trans Dielectr Electr Insulat 25(4):1195-1201

Publisher's Note Springer Nature remains neutral with regard to jurisdictional claims in published maps and institutional affiliations.

Polamraju V. S. Sobhan received the B.Tech degree in Electrical and Electronics Engineering from SVHCE, Machilipatnam, and M.E degree from Andhra University, Visakhapatnam. He is presently working in the Department of EEE, VFSTR University, Guntur, India. His 
research interests include Intelligent Controllers Design, Active Magnetic Bearings, and Bearingless drives, and Gas Insulated Substations.

Janaki Pakalapati was born in Visakhapatnam, A.P., India in 1984. She received her B.Tech degree in the Department of Electrical and Electronics Engineering from Raghu Engineering College, Visakhapatnam, India, and received her M.E. degree in Power Electronics Drives and Control in Department of Electrical and Electronics Engineering from the Andhra University College of Engineering, Visakhapatnam. She is working as Associate Professor in the Department of Electrical and Electronics Engineering at LENDI Institute of Engineering and Technology, Vizianagaram. Her main research area includes several abnormalities of spacers in Gas Insulated Substations.

Venkata Nagesh Kumar Gundavarapu received his B.E. degree from College of Engineering, Gandhi Institute of Technology and Management, Visakhapatnam, India and M.E. degree from the College of Engineering, Andhra University, Visakhapatnam. He received his doctoral degree from Jawaharlal Nehru Technological University, Hyderabad. $\mathrm{He}$ is presently working as Professor and Head in the Department of
Electrical and Electronics Engineering, JNTUA College of Engineering Pulivendula. His research interests include gas-insulated substations, Evolutionary Computation, and FACTS devices. He has published research papers in reputed National and International Journals and Conferences.

Deepak Chowdary Duvvada was born in Srikakulam, Andhra Pradesh, India. He obtained his Bachelor of Engineering degree from GITAM College of Engineering, Visakhapatnam, Andhra Pradesh, India in the year 2000 and Master of Technology degree from JNT University, Hyderabad, Andhra Pradesh, India in the year 2007. He is presently working as Professor and Principal, Dr. L. Bullayya College of Engineering for Women, Visakhapatnam, India. His research areas include Gas Insulated Substations, High Voltage Engineering, and Custom power devices.

Sravana Kumar Bali working as Assistant Professor in EEE Dept., GITAM, Vizag, A.P, India. He received his Ph.D. from JNTU Kakinada. His area of interests are Power Systems, Contingency analysis, Algorithms and FACTS Devices and Gas Insulated Substations. 